DEMOGRAPHIC RESEARCH

VOLUME 29, ARTICLE 38, PAGES 999-1038

PUBLISHED 15 NOVEMBER 2013

http://www.demographic-research.org/Volumes/Vol29/38/

DOI: $10.4054 /$ DemRes.2013.29.38

Research Article

Old age mortality in Eastern and

South-Eastern Asia

Danan Gu

Patrick Gerland

Kirill Andreev
Nan Li

Thomas Spoorenberg

Gerhard Heilig

(C) 2013 Gu, Gerland, Andreev, Li, Spoorenberg, Heilig.

This open-access work is published under the terms of the Creative Commons

Attribution NonCommercial License 2.0 Germany, which permits use, reproduction \& distribution in any medium for non-commercial purposes, provided the original author(s) and source are given credit.

See http:// creativecommons.org/licenses/by-nc/2.0/de/ 


\section{Table of Contents}

1 Introduction 1000

2 Trends in old age mortality in the region 1002

$2.1 \quad$ Life expectancies at age $65 \quad 1002$

2.2 Death rates 1006

$3 \quad$ Cause-specific death rates 1010

3.1 General trends of cause-specific death rates 1011

3.2 Contributions of causes of death to increases in life expectancies 1016

$4 \quad$ Links between mortality and socioeconomic developments 1019

5 Concluding remarks 1024

6 Acknowledgements 1027

$\begin{array}{ll}\text { References } & 1028\end{array}$

$\begin{array}{ll}\text { Appendices } & 1037\end{array}$ 


\title{
Old age mortality in Eastern and South-Eastern Asia*
}

\author{
Danan Gu ${ }^{1}$ \\ Patrick Gerland $^{2}$ \\ Kirill Andreev ${ }^{2}$ \\ $\operatorname{Nan} \mathbf{L i}^{2}$ \\ Thomas Spoorenberg $^{2}$ \\ Gerhard Heilig ${ }^{2}$
}

\begin{abstract}
BACKGROUND

Eastern and South-Eastern Asian countries have witnessed a marked decline in old age mortality in recent decades. Yet no studies have investigated the trends and patterns in old age mortality and cause-of-death in the region.
\end{abstract}

\section{OBJECTIVE}

We reviewed the trends and patterns of old age mortality and cause-of-death for countries in the region.

\section{METHODS}

We examined data on old age mortality in terms of life expectancy at age 65 and age-specific death rates from the 2012 Revision of the World Population Prospects for 14 countries in the region (China, Hong Kong, Democratic People's Republic of Korea, Indonesia, Japan, Lao People's Democratic Republic, Myanmar, Malaysia, Mongolia, Philippines, Republic of Korea, Singapore, Thailand, and Viet Nam) and data on cause-of-death from the WHO for five countries (China, Hong Kong, Japan, Republic of Korea, and Singapore) from 1980 to 2010.

\footnotetext{
* Disclaimer: Views expressed in this paper are solely those of the authors and do not necessarily reflect those of the United Nations. The country names in the study do not necessarily reflect the UN official terminology.

${ }^{1}$ United Nations Population Division, DESA. UN Plaza, DC2-1910. New York, NY 10017.

Tel: 1-917-367-9192. E-mail: gud@un.org

${ }^{2}$ United Nations Population Division, DESA. New York, NY 10017
} 


\section{RESULTS}

While mortality transitions in these populations took place in different times, and at different levels of socioeconomic development and living environment, changes in their age patterns and sex differentials in mortality showed certain similarities: women witnessed a similar decline to men in spite of their lower mortality, and young elders had a larger decline than the oldest-old. In all five countries examined for cause-of-death, most of the increases in life expectancy at age 65 in both men and women were attributable to declines in mortality from stroke and heart disease. GDP per capita, educational level, and urbanization explained much of the variations in life expectancy and cause-specific mortality, indicating critical contributions of these basic socioeconomic development indicators to the mortality decline over time in the region.

\section{CONCLUSIONS}

These findings shed light on the relationship between epidemiological transition, changing age patterns of mortality, and improving life expectancy in these populations.

\section{Introduction}

Like many other countries in the world, Eastern and South-Eastern Asian populations have witnessed a marked decline in old age mortality in recent decades. Life expectancy for both sexes combined at age 65 in Eastern Asia rose from 9.2 years in 1950-1955 to 16.8 years in 2005-2010, a net increase of 7.6 years, and the largest gain of any geographic region of the world. The corresponding gain in life expectancy at age 65 for South-Eastern Asia was 4.0 years rising from 11.2 years in 1950-1955, ranking the middle among all geographic regions in terms of gained years (United Nations Population Division(UNPOP) 2013).

Eastern and South-Eastern Asia is unique for studying old age mortality. ${ }^{3}$ First, this region is home to nearly one-third of the world's total population today, the largest region in the world (UNPOP 2013); some countries ${ }^{4}$ in the region have completed the demographic transition while many others are still undergoing transition, which provides promising data for summarizing patterns and trajectories of old age mortality over time (Bongaarts 2009; McNicoll 2006). Second, this region is economically diverse. For

\footnotetext{
${ }^{3}$ For the purpose of convenience, we sometimes term Eastern Asia and South-Eastern Asia as a single region while more often we term them as two sub-regions when we present aggregated data and compare with other major areas or the whole world.

${ }^{4}$ China, Hong Kong Special Administrative Region is territory of China. For the sake of convenience, we consider it as a country in this study.
} 
example, Japan, Hong Kong, ${ }^{5}$ and Republic of Korea are high-income economies; China and Thailand are upper middle income countries; Viet Nam and Philippines are lower middle income societies; and Myanmar is a low income country (World Bank 2011). Third, there is a substantial heterogeneity in mortality across countries in the region. Life expectancy at birth for both sexes combined in Japan, Hong Kong, Republic of Korea and Singapore was already above 80 years in 2005-2010, one of the highest in the world, whereas it was just above 64 years in Myanmar, one of the lowest ones in the world among countries not affected by the HIV/AIDS epidemic. Fourth, the low fertility and the declining mortality of populations in the region have contributed remarkably to elderly population growth. It is estimated that about $8.5 \%$ of total population in the region today are elders aged 65 or older, accounting for nearly $35 \%$ of the entire elderly population aged 65 or older of the planet. This region also accounts for $36 \%$ of the total increase in elderly population worldwide from 2010 to 2050 (UNPOP 2013).

Recent studies have shown a steady decline in adult mortality in the region, along with a wide variation within levels, trends and gender differences (Zhao 2011), yet little is known about mortality at old ages. Analyzing the trend of mortality at old ages in Eastern Asia and South-Eastern Asia helps improve our understanding about mortality and health transitions in the world using a relatively small number of countries. This paper, therefore, intends to provide a general overview of trends in mortality at old ages and the associations between mortality and socioeconomic development. For the presentation of the trends in old age mortality in Eastern and South-Eastern Asian populations, we first examine general regional trends and country-specific variations in life expectancy at age 65, and age-specific death rates for the elderly population aged 65 or older using the data from the 2012 Revision of the World Population Prospect (WPP) (UNPOP 2013). We then analyze causes of death, with a special focus on the most important causes responsible for shaping trends by age and sex based on the WHO mortality database (WHO 2011). Finally, we investigate the associations between old age mortality and socioeconomic development.

Because of issues of data availability and reliability ${ }^{6}$, we only present data on old age mortality in terms of life expectancy at age 65 and age-specific death rates for

${ }^{5}$ China, Hong Kong Special Administrative Region is abbreviated as Hong Kong hereafter.

${ }^{6}$ Japan, Hong Kong, Republic of Korea and Singapore are countries with acceptably good data, especially after 1980 (Mathers 2005). China has some underreporting problems with births in the recent few decades due to birth control policy (see Goodkind 2011), yet it has a relatively high quality of mortality data at old ages (Zeng and Gu 2008; Zeng and Vaupel 2003) in that all Han Chinese and some ethnic minorities use animal year to remember their birth dates. However, because the completeness of vital registration system in China before 1980 was around $80 \%$, and because the reliability of the 1953 and 1964 censuses is questionable (Choi and You 2004), there are no reliable official data for age-specific mortality at old ages before 1980. Similar to China, there is evidence showing that the vital registration data or the census data before 1980 in Thailand (Coale and Kisker 1986; Rukumnuaykit 2006) and Viet Nam (Merli 1998) are not very reliable, but the dates of birth have 
fourteen countries in the region from 1980 to 2010, including China, Hong Kong, Democratic People's Republic of Korea (hereafter DPR Korea), Indonesia, Japan, Lao People's Democratic Republic (hereafter Lao PDR), Myanmar, Malaysia, Mongolia, Philippines, Republic of Korea, Singapore, Thailand, and Viet Nam. ${ }^{7}$ In analyzing causes of death, only five countries (China, Hong Kong, Japan, Republic of Korea, and Singapore) were included.

\section{Trends in old age mortality in the region}

\subsection{Life expectancies at age 65}

Figure 1 shows that although life expectancy at age 65 years (hereafter $e_{65}$ ) in Eastern Asia was only slightly higher than that of the whole world for both women and men before 1995, Eastern Asia's advantage started to enlarge after 1995 with a 0.5-1.0 year gap in 2005-2010. However, older adults in Eastern Asia were disadvantaged compared to their elderly European counterparts, despite a narrowing trend after 1995. In almost all periods, South-Eastern Asia's $e_{65}$ was lower than that for all of Asia. Over the period, the gaps in $\mathrm{e}_{65}$ between South-Eastern Asia and Eastern Asia widened from 1 year to nearly 2 years for women and from 0.8 years to 1.5 years for men.

Table 1 presents $\mathrm{e}_{65}$ for the years of 1980-1985, 1995-2000 and 2005-2010 for all fourteen countries under study. Over the last thirty years, $\mathrm{e}_{65}$ increased by about one year per decade for both women and men in Eastern Asia and 0.6-0.8 years per decade in South-Eastern Asia. South-Eastern Asia had slightly greater gains for both sexes from 1980-1985 to 1995-2000, yet Eastern Asia had a much greater growth after 1995.

longstanding astrological significance among many residents in these two countries (Knodel and Chayovan 1991).

${ }^{7}$ Macao Special Administrative Region, Brunei Darussalam, Timor-Leste and Cambodia were excluded from the analyses due to the lack of reliable data on old age mortality, especially spanning several decades. 


\section{Figure 1: Life expectancy at age 65 for Eastern Asia and South-Eastern Asia,} 1980-2010

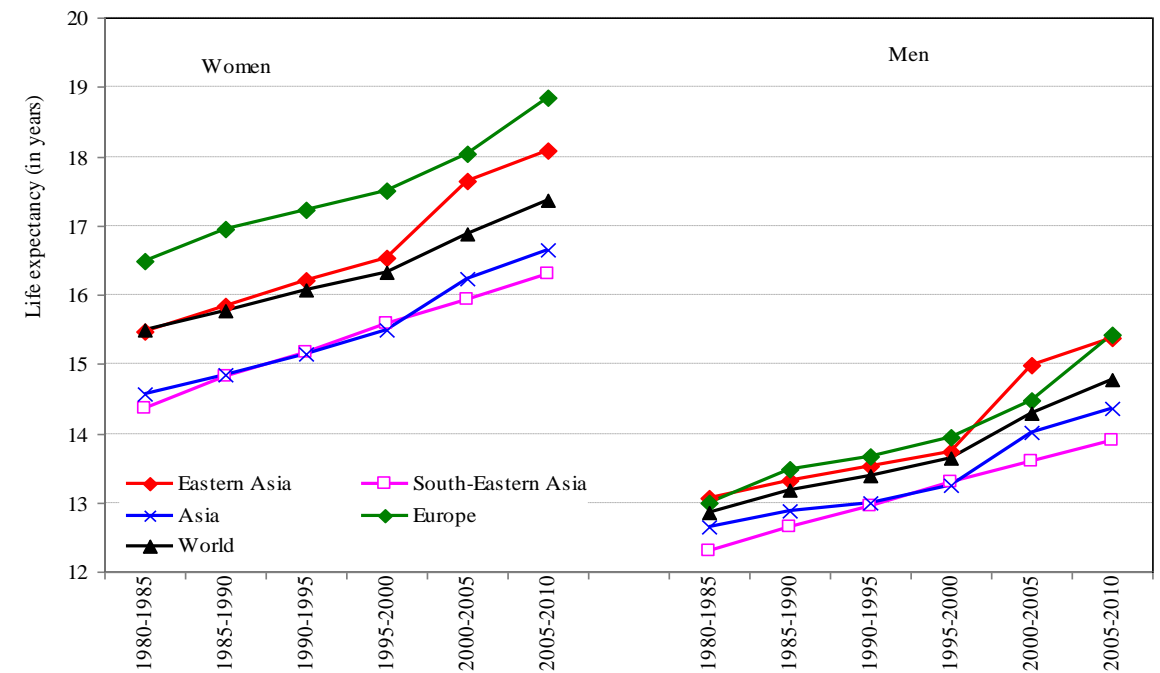

Source: UNPOP (2013).

A great variation in gains of $\mathrm{e}_{65}$ across countries was found. The greatest gains in $\mathrm{e}_{65}$ were found in Hong Kong, Japan, and Republic of Korea, where the level of $\mathrm{e}_{65}$ was relatively higher, with more than two years per decade in women and 1.5 years per decade in men. With an exception for Japanese women, the annual gain among elders in these four countries was larger after 1995. China had a much smaller gain in $\mathrm{e}_{65}$ before 1995, but a much larger gain after 1995. Mongolia had one of the largest gains in the region in the period 1995-2010, yet it had almost no gain in $\mathrm{e}_{65}$ over the whole period 1980-2010. This is because Mongolia suffered economic recession in the early 1990s due to the collapse of the former Soviet Union, which worsened Mongolia's national public health system, leading to increased mortality in the 1990s and a negative annual gain in $\mathrm{e}_{65}$ from 1980-1985 to 1995-2000. After 2000, the nation's economy has largely recovered and improved and thus mortality at old ages has started to decline. This pattern was also observed among Mongolia's adult population (Rajaratnam et al. 2010). DPR Korea only had a minor change in $\mathrm{e}_{65}$ for both sexes in 1980-2010. 
Gu et al.: Old age mortality in Eastern and South-Eastern Asia

Table 1: Life expectancy at age 65 (in years) and its annual gains (in years) in Eastern and South-Eastern Asia for selected periods, 1980-1985 to $2005-2010$

\begin{tabular}{|c|c|c|c|c|c|c|c|c|c|}
\hline & $\begin{array}{c}1980- \\
1985\end{array}$ & Rank & $\begin{array}{l}1995- \\
2000\end{array}$ & Rank & $\begin{array}{c}2005- \\
2010\end{array}$ & Rank & $\begin{array}{c}\text { Annual gain } \\
\text { from } \\
1980-1985 \text { to } \\
1995-2000\end{array}$ & $\begin{array}{c}\begin{array}{c}\text { Annual gain } \\
\text { from }\end{array} \\
1995-2000 \text { to } \\
2005-2010\end{array}$ & $\begin{array}{c}\begin{array}{c}\text { Annual gain } \\
\text { from }\end{array} \\
1980-1985 \text { to } \\
2005-2010\end{array}$ \\
\hline \multicolumn{10}{|l|}{ Women } \\
\hline Eastern Asia & 15.5 & -- & 16.5 & -- & 18.1 & -- & 0.07 & 0.16 & 0.10 \\
\hline China & 15.0 & 7 & 15.5 & 7 & 16.8 & 7 & 0.03 & 0.13 & 0.07 \\
\hline Hong Kong & 18.5 & 1 & 20.4 & 2 & 22.8 & 2 & 0.13 & 0.24 & 0.17 \\
\hline DPR Korea & 14.7 & 8 & 14.9 & 8 & 15.3 & 9 & 0.01 & 0.04 & 0.02 \\
\hline Japan & 18.3 & 2 & 21.7 & 1 & 23.6 & 1 & 0.22 & 0.20 & 0.21 \\
\hline Mongolia & 12.5 & 13 & 11.9 & 14 & 14.0 & 12 & -0.04 & 0.21 & 0.06 \\
\hline Republic of Korea & 15.6 & 6 & 17.6 & 5 & 20.7 & 4 & 0.14 & 0.30 & 0.20 \\
\hline South-Eastern Asia & 14.4 & -- & 15.6 & -- & 16.3 & -- & 0.08 & 0.07 & 0.08 \\
\hline Indonesia & 13.1 & 11 & 14.0 & 11 & 14.7 & 10 & 0.06 & 0.06 & 0.06 \\
\hline Lao PDR & 12.0 & 14 & 13.1 & 13 & 13.9 & 13 & 0.08 & 0.07 & 0.07 \\
\hline Malaysia & 13.8 & 9 & 14.8 & 9 & 15.7 & 8 & 0.07 & 0.09 & 0.08 \\
\hline Myanmar & 12.8 & 12 & 13.4 & 12 & 13.8 & 14 & 0.04 & 0.03 & 0.04 \\
\hline Philippines & 13.7 & 10 & 14.2 & 10 & 14.5 & 11 & 0.03 & 0.03 & 0.03 \\
\hline Singapore & 16.0 & 5 & 18.6 & 4 & 21.3 & 3 & 0.18 & 0.27 & 0.21 \\
\hline Thailand & 16.0 & 4 & 17.5 & 6 & 18.1 & 6 & 0.10 & 0.06 & 0.08 \\
\hline Viet Nam & 17.4 & 3 & 19.4 & 3 & 20.3 & 5 & 0.13 & 0.09 & 0.12 \\
\hline Asia & 14.6 & -- & 15.5 & -- & 16.6 & -- & 0.06 & 0.12 & 0.08 \\
\hline Europe & 16.5 & -- & 17.5 & -- & 18.8 & -- & 0.07 & 0.13 & 0.09 \\
\hline World & 15.5 & -- & 16.3 & -- & 17.4 & -- & 0.06 & 0.10 & 0.07 \\
\hline \multicolumn{10}{|l|}{ Men } \\
\hline Eastern Asia & 13.1 & -- & 13.7 & -- & 15.4 & -- & 0.04 & 0.16 & 0.09 \\
\hline China & 12.8 & 6 & 13.2 & 8 & 14.7 & 7 & 0.02 & 0.16 & 0.08 \\
\hline Hong Kong & 14.4 & 2 & 16.5 & 2 & 18.2 & 2 & 0.14 & 0.17 & 0.15 \\
\hline DPR Korea & 10.0 & 14 & 9.5 & 14 & 10.3 & 14 & -0.03 & 0.08 & 0.01 \\
\hline Japan & 15.1 & 1 & 17.0 & 1 & 18.6 & 1 & 0.13 & 0.16 & 0.14 \\
\hline Mongolia & 11.3 & 11 & 10.4 & 13 & 11.3 & 13 & -0.06 & 0.09 & 0.00 \\
\hline Republic of Korea & 10.9 & 13 & 13.8 & 6 & 16.6 & 4 & 0.19 & 0.29 & 0.23 \\
\hline South-Eastern Asia & 12.3 & -- & 13.3 & -- & 13.9 & -- & 0.07 & 0.06 & 0.06 \\
\hline Indonesia & 11.7 & 9 & 12.5 & 9 & 13.0 & 9 & 0.05 & 0.05 & 0.05 \\
\hline Lao PDR & 10.9 & 12 & 11.9 & 12 & 12.6 & 10 & 0.07 & 0.07 & 0.07 \\
\hline Malaysia & 12.9 & 5 & 13.6 & 7 & 14.1 & 8 & 0.04 & 0.05 & 0.05 \\
\hline Myanmar & 11.4 & 10 & 12.0 & 11 & 12.3 & 11 & 0.04 & 0.03 & 0.04 \\
\hline Philippines & 12.0 & 8 & 12.1 & 10 & 12.2 & 12 & 0.01 & 0.01 & 0.01 \\
\hline Singapore & 12.6 & 7 & 15.3 & 4 & 17.7 & 3 & 0.18 & 0.24 & 0.20 \\
\hline Thailand & 13.8 & 3 & 15.5 & 3 & 16.0 & 5 & 0.11 & 0.05 & 0.09 \\
\hline Viet Nam & 13.5 & 4 & 14.7 & 5 & 15.4 & 6 & 0.08 & 0.07 & 0.08 \\
\hline Asia & 12.7 & -- & 13.2 & -- & 14.4 & -- & 0.04 & 0.11 & 0.07 \\
\hline Europe & 13.0 & -- & 13.9 & -- & 15.4 & -- & 0.06 & 0.15 & 0.10 \\
\hline World & 12.9 & -- & 13.6 & -- & 14.8 & -- & 0.05 & 0.11 & 0.08 \\
\hline
\end{tabular}

Source: UNPOP (2013).

With the exception of Singapore, which is similar to Hong Kong, Japan and Republic of Korea, countries in South-Eastern Asia were more homogeneous and the 
annual changes in two periods were mostly similar. Despite a 2-3 per cent HIV/AIDS prevalence among young adults in Thailand, nearly one year per decade was added to $\mathrm{e}_{65}$ for both women and men. Vietnam also had a relatively large gain in $\mathrm{e}_{65}$, whereas Philippines had the smallest growth. The annual increase in $\mathrm{e}_{65}$ in other countries in South-Eastern Asia was more or less similar to the average growth of this sub-region.

Table 2 shows that there was a gender difference in $\mathrm{e}_{65}$ (women's minus men's) that enlarged from 1980 to 2010 for both Eastern Asia (from 2.4 years to 2.7 years) and South-Eastern Asia (from 2.1 years to 2.4 years). In Eastern Asia, China and Mongolia had the smallest gender gap (1.2-2.7 years), while Japan and both Koreas had the largest (3.2-5.5 years). The change in gender differences over time also varied: Japan and Mongolia experienced an increasing gap in the study period, whereas Hong Kong and DPR Korea had a declining trend and other countries witnessed a fluctuation. With exceptions for Singapore and Vietnam, the gender gap in $\mathrm{e}_{65}$ over the study period for all other countries in South-Eastern Asia was less than 2.5 years with the lowest around 1.2-1.3 years. Although both Eastern Asia and South-Eastern Asia had a greater gender gap in $\mathrm{e}_{65}$ as compared to the whole Asia, they had a smaller gender gap than Europe from 1980-1985 to 2005-2010 and the world from 1980-1985 to 1990-1995. Since 1995, the gender gaps in $\mathrm{e}_{65}$ in Eastern Asia have exceeded that of the world.

Table 2: Gender difference (years) in life expectancy at age 65 in Eastern and South-Eastern Asia

\begin{tabular}{lcccccc}
\hline & \multicolumn{5}{c}{ Women's life expectancy -men's life expectancy (years) } \\
\cline { 2 - 7 } & $\mathbf{1 9 8 0 - 1 9 8 5}$ & $\mathbf{1 9 8 5 - 1 9 9 0}$ & $\mathbf{1 9 9 0 - 1 9 9 5}$ & $\mathbf{1 9 9 5 - 2 0 0 0}$ & $\mathbf{2 0 0 0 - 2 0 0 5}$ & $\mathbf{2 0 0 5 - 2 0 1 0}$ \\
\hline Eastern Asia & 2.40 & 2.52 & 2.67 & 2.80 & 2.67 & 2.72 \\
China & 2.14 & 2.20 & 2.25 & 2.30 & 2.03 & 2.04 \\
Hong Kong & 4.14 & 4.06 & 3.98 & 3.88 & 3.89 & 4.64 \\
Dem. People's Rep. of Korea & 4.74 & 4.81 & 5.46 & 5.39 & 5.03 & 4.98 \\
Japan & 3.21 & 3.57 & 4.04 & 4.64 & 4.99 & 5.03 \\
Mongolia & 1.22 & 1.20 & 1.82 & 1.53 & 2.54 & 2.66 \\
Republic of Korea & 4.68 & 4.16 & 4.03 & 3.85 & 3.87 & 4.04 \\
South-Eastern Asia & 2.06 & 2.17 & 2.22 & 2.30 & 2.35 & 2.40 \\
Indonesia & 1.35 & 1.42 & 1.48 & 1.54 & 1.60 & 1.65 \\
Lao People's Dem. Republic & 1.12 & 1.14 & 1.18 & 1.22 & 1.25 & 1.29 \\
Malaysia & 0.85 & 0.99 & 1.13 & 1.25 & 1.38 & 1.68 \\
Myanmar & 1.42 & 1.43 & 1.43 & 1.44 & 1.44 & 1.45 \\
Philippines & 1.72 & 1.85 & 1.98 & 2.10 & 2.23 & 2.35 \\
Singapore & 3.35 & 2.54 & 2.86 & 3.37 & 3.39 & 3.64 \\
$\quad$ Thailand & 2.20 & 2.37 & 2.05 & 2.03 & 2.11 & 2.08 \\
$\quad$ Viet Nam & 3.95 & 4.19 & 4.45 & 4.69 & 4.81 & 4.90 \\
Asia & 1.91 & 1.95 & 2.14 & 2.25 & 2.22 & 2.29 \\
Europe & 3.50 & 3.47 & 3.57 & 3.56 & 3.55 & 3.42 \\
World & 2.62 & 2.60 & 2.70 & 2.68 & 2.59 & 2.58 \\
\hline
\end{tabular}

Source: UNPOP (2013). 


\subsection{Death rates}

Figures $2 \mathrm{a}$ and $2 \mathrm{~b}$ show that Eastern Asia had a larger decline in old age mortality from 1980-1985 to 2005-2010 than South-Eastern Asia for all three age groups. ${ }^{8}$ In the last three decades, old age mortality in Eastern Asia had a similar or even greater reduction compared to Asia, Europe, and the world for both women and men, whereas old age mortality in South-Eastern Asia experienced a smaller comparative reduction. Generally speaking, young elders had a larger decline than the oldest-old for both men and women. Republic of Korea, Hong Kong, Japan, and Singapore were the four countries that had the largest overall declines in death rates in the region for all three age groups and for both sexes from 1980-1985 to 2005-2010, which were 2.0-3.0 times as great as those of Asia, Europe and the world. Considering that these four societies had a relatively high life expectancy at birth for both men and women at the beginning of the period, such a large reduction indicates that a moderate improvement in old age mortality is still possible even in the very low mortality countries.

Figure 3 shows that the greater decline in old age mortality in Eastern Asia over South-Eastern Asia by period is also confirmed by birth cohort (see (a) and (b) in Figure 3). ${ }^{9}$ Men's patterns were not shown because they were very close to those of women's. The improvement in death rate by cohort from 1980-1985 to 2000- 2005 in Hong Kong, Japan, Republic of Korea and Singapore was the largest in the region, and was as remarkable as the improvement by period. There was a relatively large reduction among younger cohorts in Mongolia (Figure 3(f)), yet a crossover was found among older cohorts because of an economic crisis in the 1990s, which offset the period improvement. A crossover among older cohorts in Thailand was also observed (Figure $3(\mathrm{~g})$ ), possibly because of reduced health care resources among elderly population as country's greater resources were pooled in fighting against HIV/AIDS among younger populations.

\footnotetext{
${ }^{8}$ To better understand the trend of improved life expectancy in elderly population in Eastern and South-Eastern Asia, we present death rates for age groups 65-74, 75-84 and 85+ by sex for each of seven countries from 1980-1985 to 2005-2010 (see Figures $2 \mathrm{a}$ and $2 \mathrm{~b}$ ). The sex-specific death rates for these three age groups were calculated from life expectancies at ages $65,70,75,80$ and 85 , together with the life table survivors $(l x)$ at ages $65,70,75,80,85$ from the 2012 Revision of the WPP.

${ }^{9}$ Note that the death rate for a five-year age group in the 2012 revision of the WPP refers to a five-year period (e.g., 1995-2000), not to a single calendar year. Therefore, the corresponding birth cohort for each five-year age group in every five-year period could refer to a birth cohort born in a ten-year period, somewhat overlapping with its neighboring five-year age groups.
} 
Figure 2: Proportion declined for age-specific death rate among elderly population in 2005-2010 as compared to 1980-1985, Eastern and South-Eastern Asia

a. Women

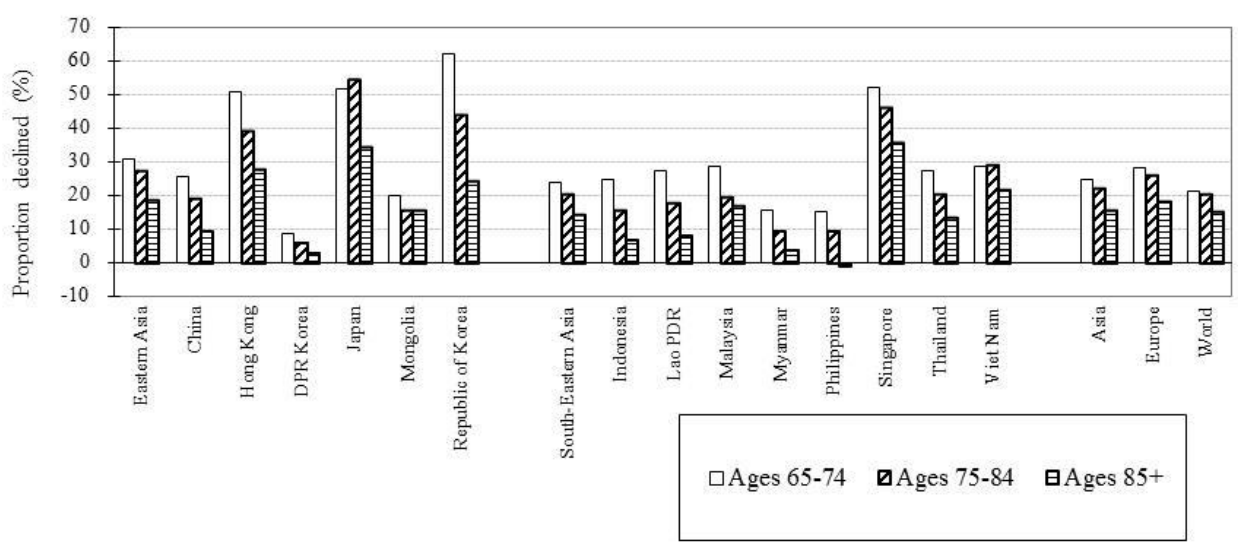

b. Men

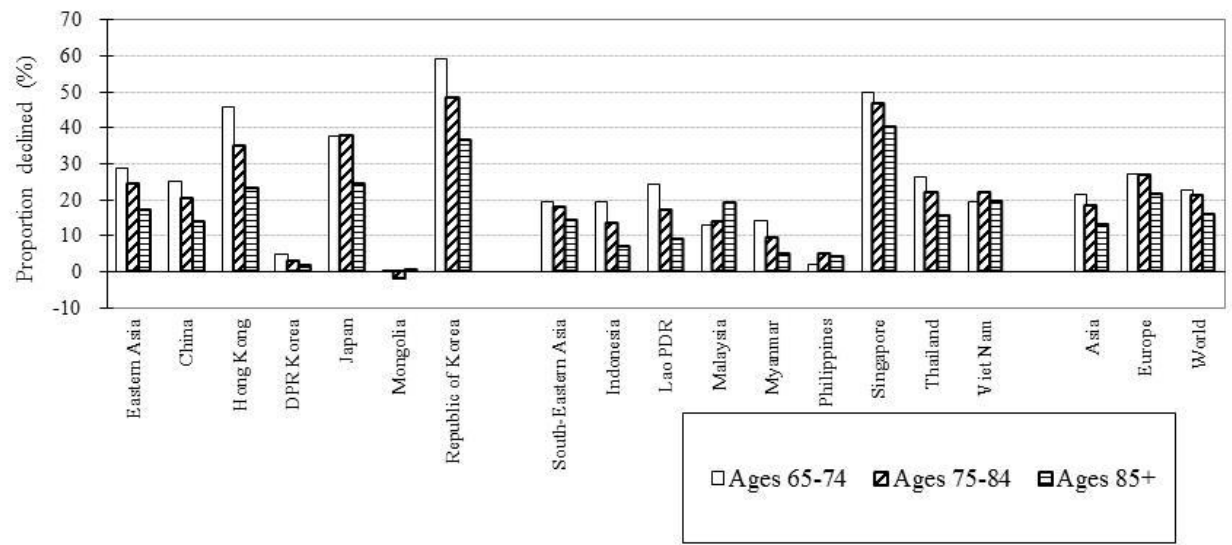

Source: UNPOP (2013). 
Gu et al.: Old age mortality in Eastern and South-Eastern Asia

Figure 3: Women's age-specific death rates by birth cohort for selected countries, 1980-2010

a. Eastern Asia

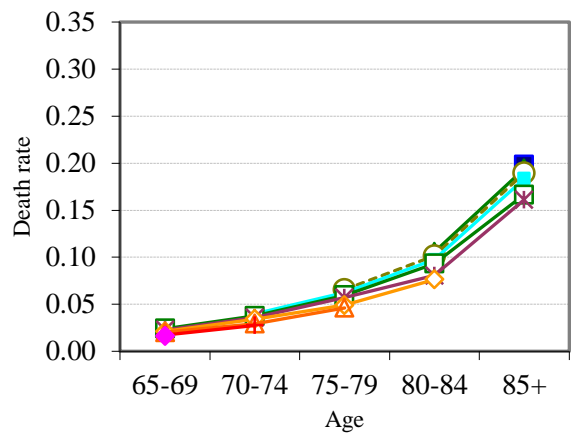

c. Hong Kong

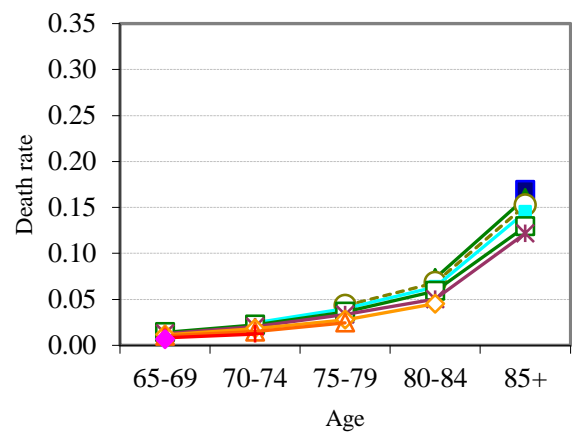

e. Republic of Korea

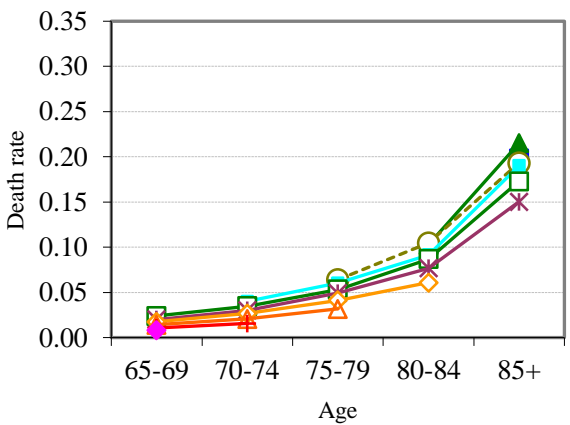

b. South-Eastern Asia

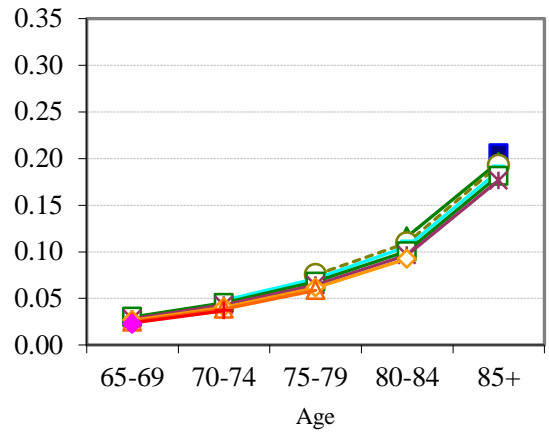

d. Japan

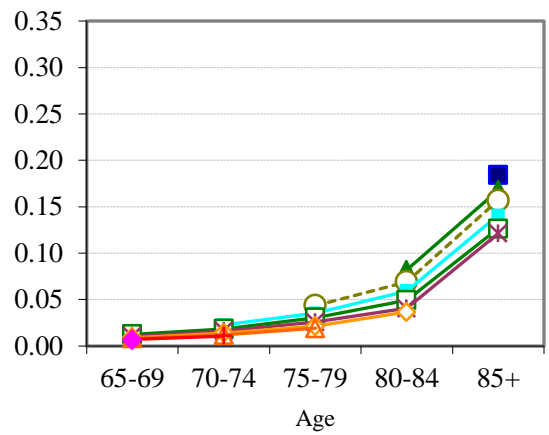

f. Mongolia

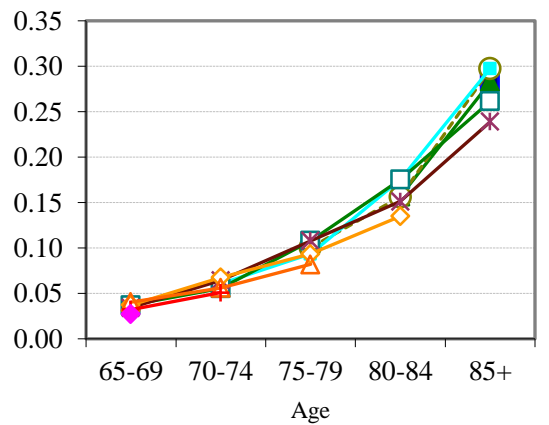




\section{Figure 3: (Continued)}

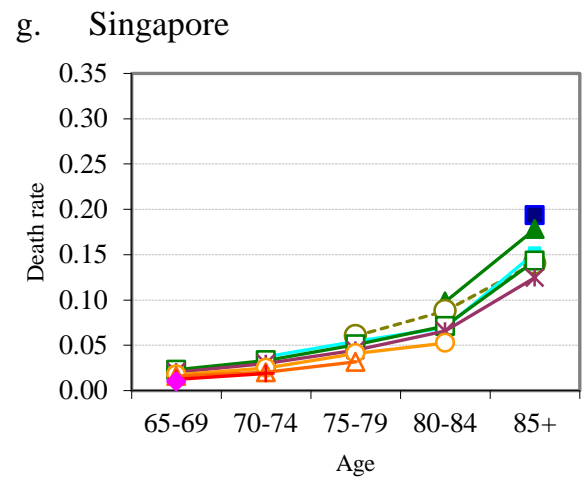

h. Thailand

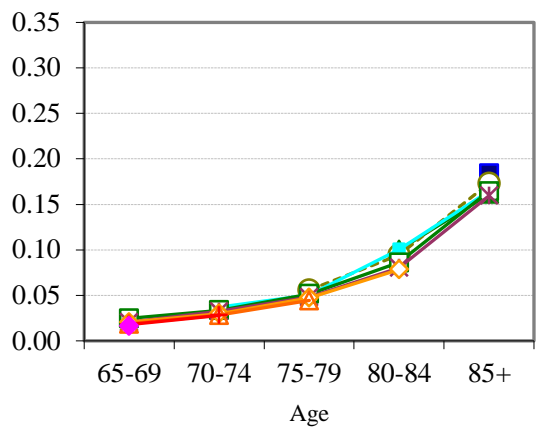

Birth Cohorts

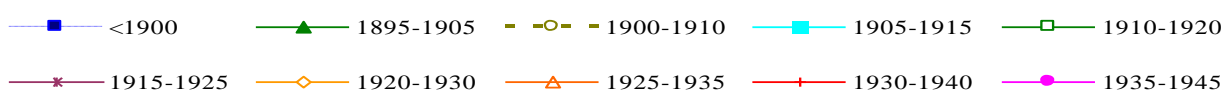

Source: UNPOP (2013).

In summary, all studied countries in Eastern and South-Eastern Asia experienced an increase in life expectancy at age 65 and a decline in mortality at old ages in the study period. However, relative mortality improvements were more drastic among young elders than among the oldest-old, especially for men, which is in accordance with one recent study in some European countries (Janssen, Kunst, and Mackenbach 2007). This is probably because the mortality process selected frail people at younger ages, leaving more robust individuals to survive to very old ages, causing a ceiling effect for reduction in mortality at these ages (Janssen, Kunst, and Mackenbach 2007). Higher income countries (e.g., Hong Kong, Japan, Republic of Korea, and Singapore) tended to witness a greater reduction in mortality than other lower income countries in the region. We will discuss this in Section 4. Women had a decline similar to men's, despite their lower level of mortality. The sex differential in mortality is likely to have been affected by combinations of gender differences in biological and genetic makeup and exposures to the risks of morbidity and mortality, such as different gender roles in production activities and human reproduction, different status in the family and society, and differences in risky behaviors between men and women (Rogers et al. 2010; Staetsky 2009; Zhao 2011). When mortality reaches a moderate or low level through improved nutrition, public health measures, and better health care and education, women's 
Gu et al.: Old age mortality in Eastern and South-Eastern Asia

environmental disadvantage is largely reduced and genetic-biological factors likely favor women's longevity (Lopez 1984).

\section{Cause-specific death rates}

Causes of death from 1980 to 2010 for five countries (China, Hong Kong, Japan, Republic of Korea, and Singapore) in the region with available and relatively reliable data on number of age-sex-specific deaths by cause and the corresponding population from the WHO mortality database were examined..$^{10}$ Because different countries used different revisions of the ICD in different years and because there was some degree of uncertainty in identifying and classifying causes of death statistics (Luy et al. 2011), we regrouped causes into seven broad categories consisting of stroke (cerebrovascular), heart diseases (cardiovascular), cancer (malignant neoplasm), diabetes, respiratory diseases, all infectious diseases and all other causes. ${ }^{11}$

${ }^{10}$ The codes of causes of death in the study period cover the $9^{\text {th }}$ and $10^{\text {th }}$ revisions of the International Classification of Diseases (ICD) (WHO 2011). The inclusion of China was based on two considerations: the empirical evidence on reliable data for causes of death in China (Rao et al. 2005). Thailand was included at the initial design. Yet it was finally excluded because of the mortality discrepancy between two sources. There is evidence showing an under-registration in death in Thailand, even in the 2000s (Vapattanawong and Prasartkul 2011). More importantly, because the proportion of ill-defined causes (Causes of death either unknown (including "sudden death") or imprecise (including just symptoms or laboratory test results)) (e.g., codes R00-R99 in ICD-10; codes B46 serial in ICD-9B, and code C081 in ICD-9 for China) out of the total deaths in Thailand was around $51 \%$ for the elderly population in the 1980 s, ranging from $25 \%$ in ages $65-69$ to nearly $80 \%$ in ages $85+$, and around $40 \%$ from 1995 to 2005 , ranging from $15 \%$ in ages $65-69$ to $75 \%$ in ages $85+$. In contrast, the shares of ill-defined causes in elderly population were only around $2 \%$ in China, Hong Kong, Japan and Singapore and about 10\% in Republic of Korea in 1980-2005. The other countries were excluded from the cause-specific analyses either because of unavailability of data or because of unreliable data. The coverage of WHO mortality data for five countries/territories vary greatly from less than $10 \%$ for China to nearly $100 \%$ in Japan (see Appendix Table A-1).

${ }^{11}$ Details about the recoding of causes of death and the data availability for five countries are provided in Appendix Table B-1. We also classified the WHO mortality data into five-year periods, but applied the notation criterion used by the 2012 Revision of the WPP to produce five-year periods for cause-specific death rates, labeled as 1980-1985, 1985-1990, and so forth. Assessments for all-cause death rates by age and sex between two independent data sources (i.e., the 2012 Revision of the WPP and the WHO mortality database) yielded a reasonable agreement (see Appendix Figure C-1). However, to account for the possible underestimation of mortality at the oldest-old ages in some countries in the WHO dataset, and to maintain the consistency across all age groups, an adjustment was made for cause-specific death rate. Specifically, we first estimated the age-sex-specific compositions of causes of death for each period and each country based on the WHO mortality data. We then applied these compositions to the age-sex-specific death rates estimated from the 2012 Revision of the WPP as indicated earlier so that the summation of adjusted age-sex-cause-specific death rates was equal to the total age-sex-specific death rates in the WPP, for the corresponding period and the country. 


\subsection{General trends of cause-specific death rates}

Figure 4 provides the age standardized cause-specific death rates of population aged 65 or older by sex for five countries from 1980-1985 to 2005-2010 using the age-sex-specific population distribution of Eastern Asia and South-Eastern Asia in 2010 from the 2012 Revision of the WPP. ${ }^{12}$ We found that deaths due to circulatory diseases (i.e., stroke and heart diseases) accounted for $30-40 \%$ of total deaths in women and $20-40 \%$ of total deaths in men in most time periods. However, in Republic of Korea and China, stroke mortality was higher than heart disease mortality; whereas in Hong Kong, Japan, and Singapore, heart disease mortality was higher than stroke mortality. Figure 4 also shows that mortality due to stroke decreased for both men and women over the study period, especially in Hong Kong, Japan, Republic of Korea, and Singapore, where the overall mortality due to stroke among older adults aged 65 or older dropped by more than $50 \%$ in the study period. Mortality due to heart diseases in these five countries also showed a downward trend, especially in Japan and Republic of Korea where heart disease mortality dropped by half.

The decrease in cancer mortality was far less pronounced than that for mortality due to stroke and heart diseases, with the greatest declines among women in Japan and Hong Kong. Men's cancer mortality in these two countries had a less significant decline than that of women. Cancer mortality in the other four countries either had no change, or increased for both women and men (see Figures 4 and 5). Among the oldest-old aged 85 or older, cancer mortality increased in all countries in both men and women, indicating that cancer mortality is undergoing a shift from younger ages to oldest-old ages.

It is interesting to note that diabetes mortality in Republic of Korea was higher than in other five countries and that there was a notable increase in mortality due to diabetes in China and Republic of Korea. Indeed, diabetes mortality in China and Republic of Korea increased universally for every age group for both sexes in the 2000s as compared to the 1980s (see Figure 5). Diabetes mortality in these two countries doubled in the study period in almost all cases. In the case of older women aged 80 or older in Republic of Korea, diabetes mortality in the $2005-2010$ was nearly five times as high as in the 1985-1990. This fast increase deserves more attention.

${ }^{12}$ If the ratio is greater than one, it indicates that the mortality for a specific cause increased from 1980-1985 to 2005-2010 and vice versa. 
Figure 4: $\quad$ Age standardized causes of death among elderly population aged 65 or older for five countries in Eastern and South-Eastern Asia, 1980-2010

a. China

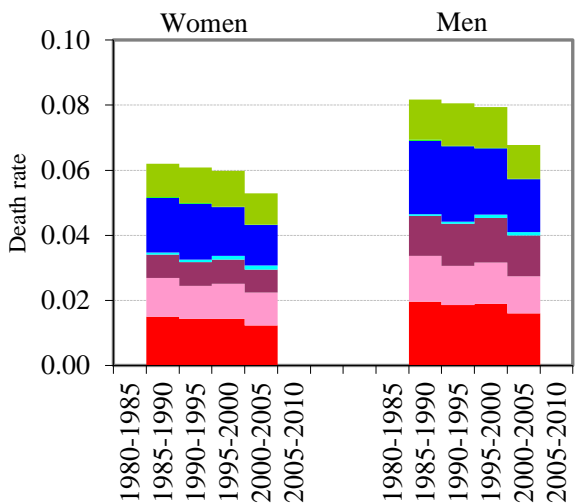

c. Japan

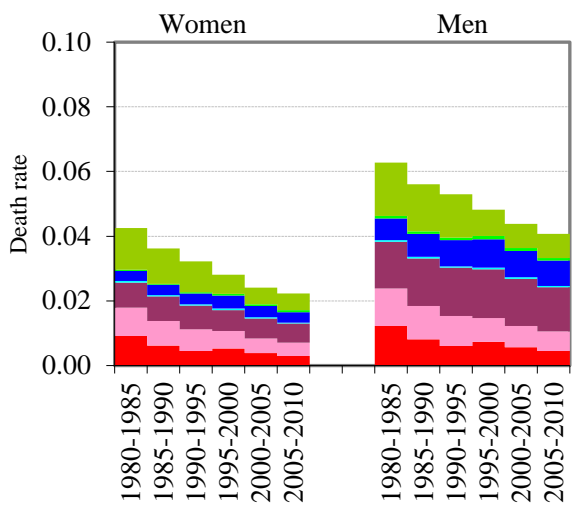

b. Hong Kong

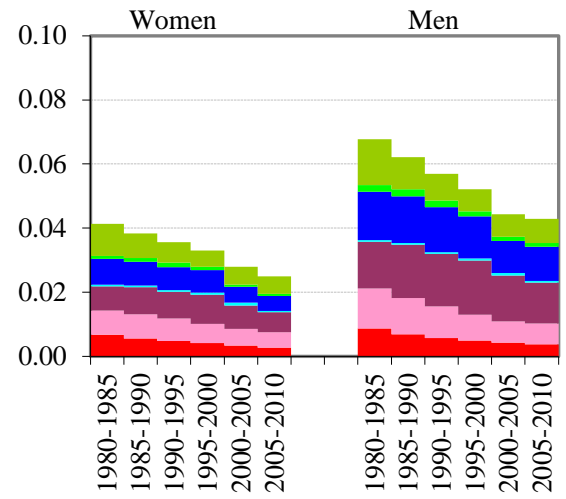

d. Republic of Korea

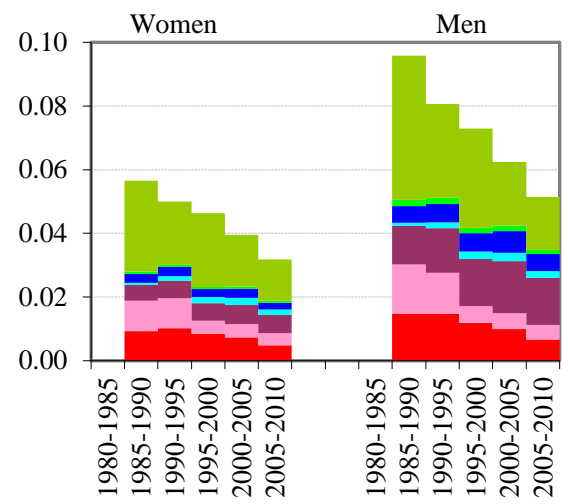




\title{
Figure 4: (Continued)
}

e. Singapore

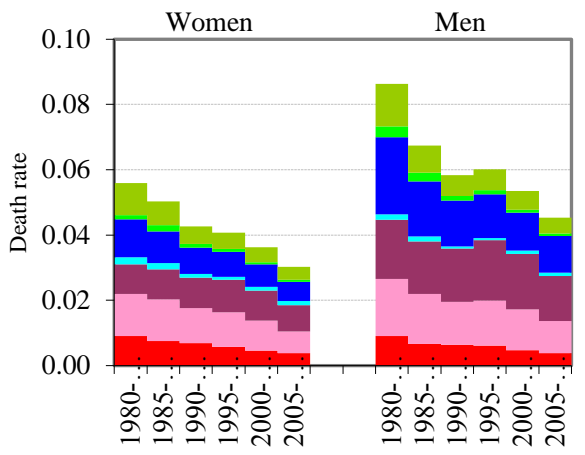

\author{
$\square$ All Other Causes \\ 口Infectious Disease \\ - Respiratory Diseases \\ 口Diabetes \\ 口Cancers \\ 口Heart Diseases \\ aStroke
}

Sources: WHO (2011) and UNPOP (2013).

Note: Causes of death recoded into broad categories by the authors.

China, Hong Kong, and Singapore had a slight decline in mortality due to respiratory diseases for both men and women. Whereas an increase in mortality due to respiratory diseases was observed among Japanese and Korean older men, a decrease or fluctuation trend was found among older women in these two countries.

Compared to the levels of mortality due to other causes, the levels of mortality due to either diabetes or infectious diseases were relatively small. Mortality due to infectious diseases in China was substantially reduced in the study period, yet this trend must be interpreted cautiously because the number of deaths from infectious diseases is small, especially as our estimates were obtained from the sample covering less than $10 \%$ of the total population. In the other four countries, the changes in mortality due to infectious diseases were small as well. Figure 5 further demonstrates that, with an exception for infectious diseases mortality in China, the reductions in mortality by cause were mostly found in younger elders of both sexes in every country, which is consistent with the findings in Section 2. 
Figure 5: Ratios of death rate by cause and age for five countries in the region

a. China

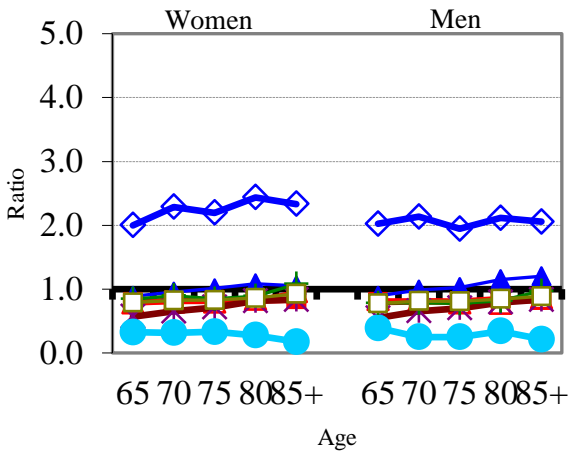

c. Japan

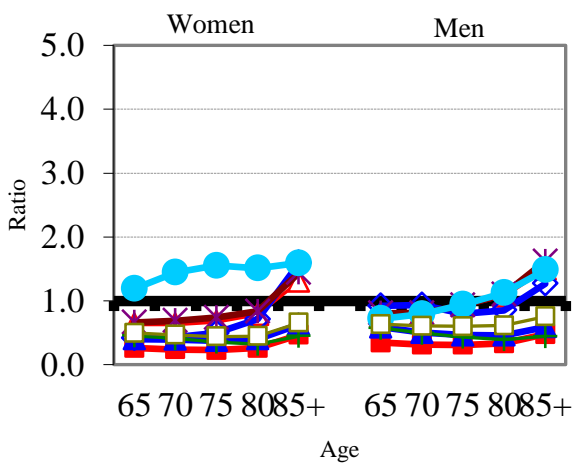

b. Hong Kong

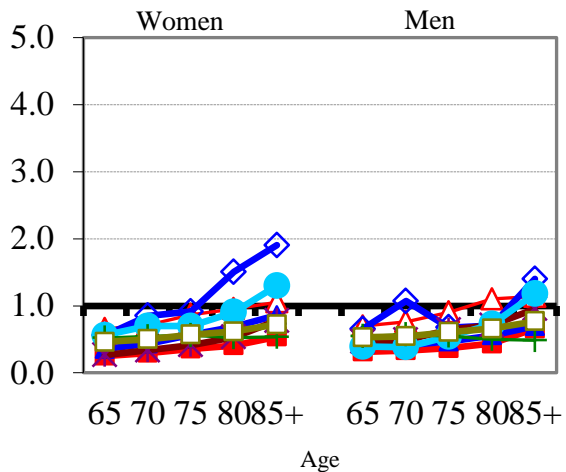

d. Republic of Korea

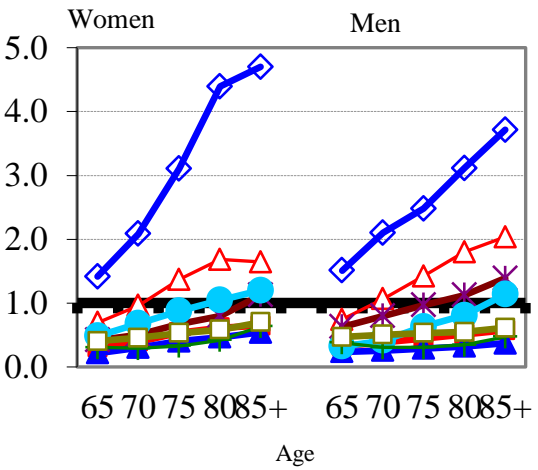




\section{Figure 5: (Continued)}

e. Singapore

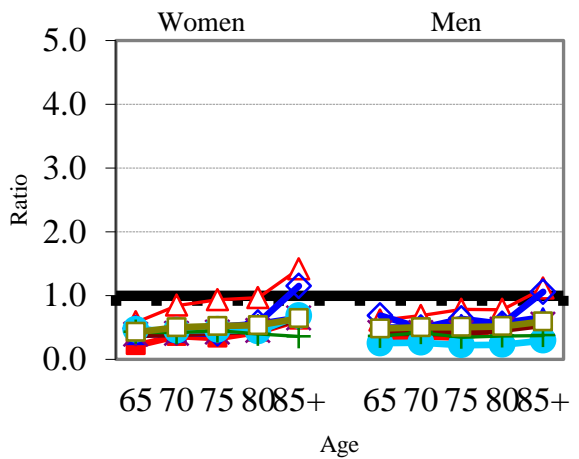

Note: (1) Death rates were measured by five-year age groups except for ages $85+$. (2) Ratios referred to 2000 versus $1987-1989$ for China, 2005-2009 versus 1985-1989 for Republic of Korea, and 2005-2009 versus 1980-1984 for all other countries. Sources: UNPOP (2013) and WHO (2011).

Overall, the leading causes of deaths of older adults in these five countries tended to be dominated by chronic and degenerative diseases, a similar profile found in elderly populations in Europe and North America since 1950 (Mladovsky et al. 2009; Sahyoun et al. 2001). However, there was a great variation in composition of age-standardized causes of deaths across the five countries over the study period. Respiratory disease persistently ranked as the top leading cause in Chinese elders over the study period, which is typical in low-income countries (WHO 2008). In contrast, either stroke or heart diseases ranked as the top leading cause in Hong Kong, Japan, Republic of Korea and Singapore before 1990 and cancer (malignant neoplasm) after 1990, which is typical in middle- or high-income countries (WHO 2008). 


\subsection{Contributions of causes of death to increases in life expectancies ${ }^{13}$}

Figure 6 reveals that reductions in mortality due to stroke and heart diseases added 1.7 years and 1.2 years respectively to Japanese women's $\mathrm{e}_{65}$ from 1980-85 to 2005-2010. This was a tremendous gain in $\mathrm{e}_{65}$ considering that Japan is one of the countries with the longest life expectancy and that this amount is 0.5 years more than the total gain in women's life expectancy at age 65 from 1980 to 2010 in Europe, a region with the highest life expectancy in the world today. Contributions due to decreases in stroke and heart disease mortality in Hong Kong, Republic of Korea and Singapore also mattered, but in a lesser degree. The decline in mortality due to these two causes in China contributed 0.5-0.6 years to $\mathrm{e}_{65}$ for both men and women; the gain was much smaller in absolute terms there than in the other four countries, but the relative contribution of these two causes was similar to that of the other four countries. The result provides a clear picture of the leading role of circulatory diseases in reducing the mortality level in these countries in the past two or three decades.

While mortality due to respiratory diseases did not change much in Japan and Republic of Korea, the decreases in respiratory diseases led to an increase in women's $\mathrm{e}_{65}$ by 0.65 years in China, 0.9 years in Hong Kong and 1.2 years in Singapore. The contribution of the decline in respiratory diseases to $e_{65}$ in China was the largest, greater than stroke and heart diseases combined. The contribution of reduction in cancer mortality to $e_{65}$ was relatively small in the five countries and even negative in both women and men in Republic of Korea and men in China. Given the relatively high level of cancer mortality, its trend in the past two or three decades in these five countries has posed a challenge for them to fight against cancer mortality in the future. Contributions

${ }^{13}$ The contributions of disease-specific causes of death to the changes in life expectancy at age 65 were estimated using an actuarial method of decomposing mortality rates proposed by Pollard (1982). This method is a popular decomposition approach to quantify contribution from changes in age or disease-specific mortality. The following formula is employed to fulfill this goal:

$$
\Delta^{2-1}=e_{65}^{2}-e_{65}^{1}=\sum_{i=1}^{7}\left[0.5^{*}\left(\Delta e_{65}^{i^{\prime}}+\Delta e_{65}^{i^{\prime \prime}}\right)\right]=0.5^{*} \sum_{i=1}^{7}\left[\left(e_{65}^{i^{\prime}}-e_{65}^{1}\right)+\left(e_{65}^{2}-e_{65}^{i^{\prime \prime}}\right)\right],
$$

where $e_{65}^{1}$ and $e_{65}^{2}$ are the life expectancies at age 65 for time 1 and time $2 ; i$ denotes cause $i ; e_{65}^{i^{\prime}}$ is hypothetical life expectancy at age 65 if only mortality rate for cause $i$ was changed from time 1 to time 2 with mortality rates for all other causes unchanged; $e_{65}^{i^{\prime \prime}}$ is the hypothetical life expectancies at age 65 if mortality rates due to all causes except $i$ were changed from time 1 to time 2; $\omega$ is the highest age (i.e., ages $85+$ herein); $\Delta e_{65}^{i^{\prime}}$ indicates the gain or loss in life expectancy at age 65 if only mortality rate for cause $i$ was changed from time 1 to time 2 with mortality rates for all other causes unchanged as compared to life expectancy at age 65 at time $1 ; \Delta e_{65}^{i^{\prime \prime}}$ indicates the gain or loss in life expectancy at age 65 if mortality rates for all causes except $i$ were changed from time 1 to time 2 as compared to life expectancy at age 65 at time 2 . In estimating $e_{65}^{i^{\prime}}$ and $e_{65}^{i^{\prime \prime}}$, we applied a weight to the numbers of person-year lived in every age groups. The weight is determined by the mortality level in these two scenarios with respective to actual mortality levels in time 1 and time 2. A similar method was used by several previous studies (see Beltrán-Sánchez, Preston, and Canudas-Romo 2008; Gomez-Redondo and Boe 2005; Klenk et al. 2007). 
from causes of diabetes and infectious diseases were trivial to $\mathrm{e}_{65}$ compared to other causes. However, considering the fast increase in mortality due to diabetes in China and Republic of Korea, more attention should be paid to this type cause of death in the near future. It has been reported that the prevalence of obesity in both China and Republic of Korea among young generations has increased greatly in the past one or two decades because of Westernized diet, low levels of physical activity, and high levels of tobacco consumption (Lee 2012; Popkin, Horton, and Kim 2001; Wu 2006). If the trend of obesity continues without medical technology breakthrough, the increase in mortality from diabetes in the future will persist and certainly be a potential threat to public health.

It is noteworthy that mortality due to causes not-analyzed in this study (i.e., all other causes) in China did not contribute substantially to the total gain in $\mathrm{e}_{65}$, which is different from all other countries where the decline in all other diseases contributed the greatest share to gains in $\mathrm{e}_{65}$. Decreases in stroke, heart disease, and respiratory diseases in China, accounted for more than $90 \%$ of the total gain in $\mathrm{e}_{65}$. It is also worthy to note that Japanese older men and women aged 65-79 witnessed a reduction in mortality due to respiratory diseases, yet changes in mortality due to respiratory diseases contributed to about 0.1 years and 0.2 years of loss in $\mathrm{e}_{65}$ because of increase in mortality among elders aged 80 or older. Similar cases were found for cancer in men in China, diabetes in women in Hong Kong and respiratory diseases for men in Republic of Korea. In other cases, the reduction in mortality at younger ages outweighed the increase in mortality at older ages, which produced a positive gain to $\mathrm{e}_{65}$.

\section{Figure 6: Contributions (in years) of causes of death to life expectancy at age 65 from 1980-1985 to 2005-2010 for selected countries, Eastern and South-Eastern Asia}

a. China

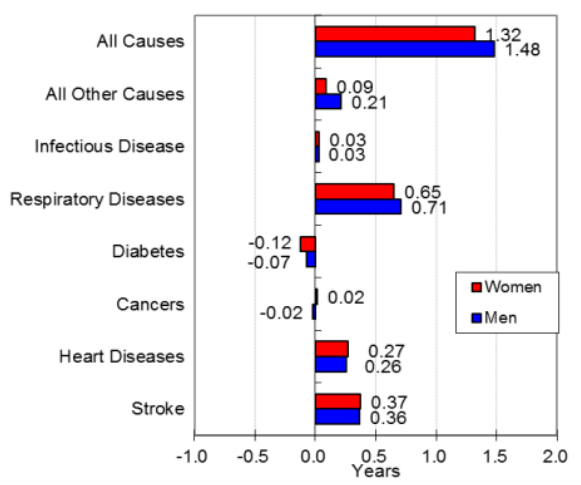

b. Hong Kong

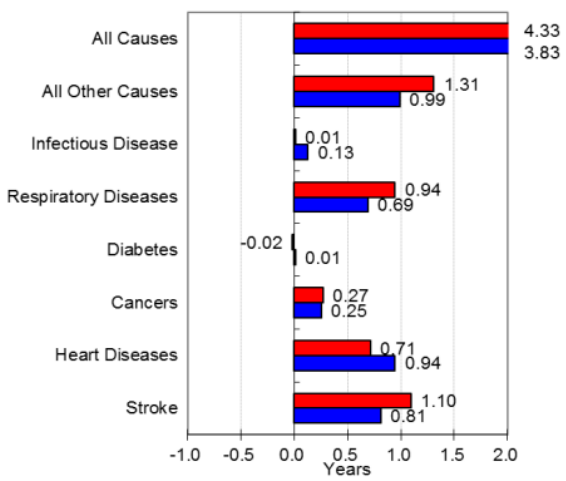




\section{Figure 6: (Continued)}

c. Japan

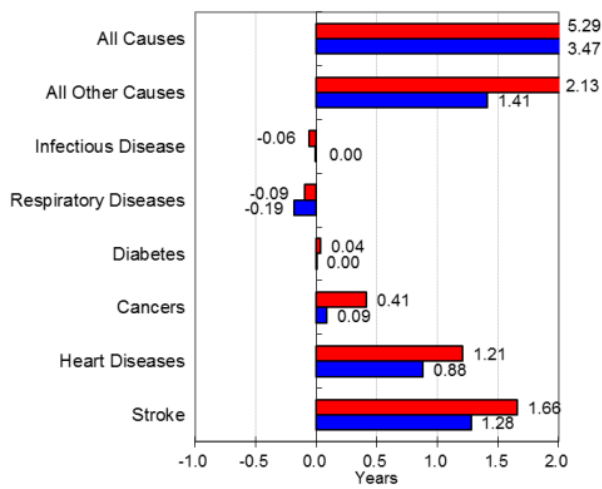

d. Republic of Korea

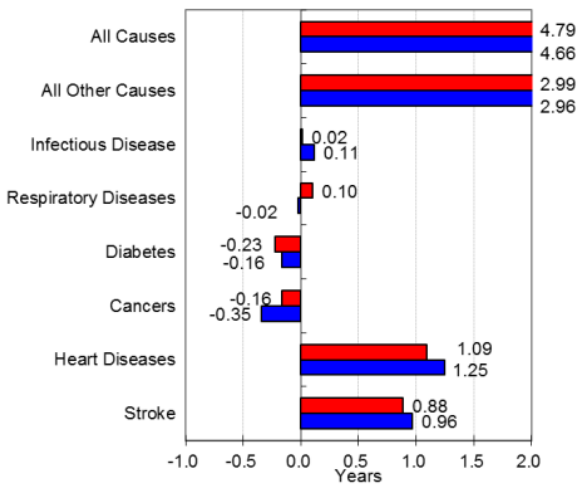

e. Singapore

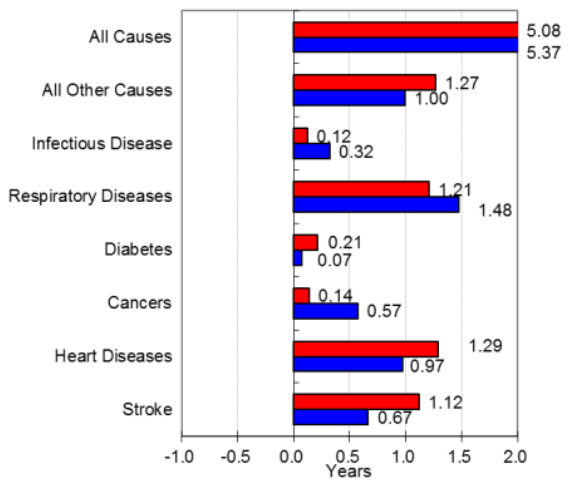

Note: Data were from 1987-1989 to 1995-2000 for China and from 1985-1989 to 2005-2009 for Republic of Korea. Sources: Cause-specific death rates and total death rates were from UNPOP(2013) and WHO (2011). Contributions were calculated by the authors.

To conclude, we found that deaths from stroke, heart diseases, cancer, and respiratory diseases constituted most of the total deaths in the study period, in both men and women. According to the epidemiological transition or health transition theory (Omran 1971; 1998), deaths from cerebrovascular and cardiovascular diseases, cancers, and other non-communicable diseases increasingly become leading causes after mortality due to infectious diseases reaches a low level. The general trend in the composition of causes of death at old age demonstrated in these five Eastern and 
South-Eastern Asian countries in the recent few decades can be considered as a cerebrovascular and cardiovascular revolution, or, the age of delayed degenerative diseases (Olshansky and Ault 1986; Robine 2001), similar to the ones observed in some countries in Europe (Glei, Meslé, and Vallin 2010; Janssen et al. 2004; Mackenbach and Garssen 2010; Vallin and Meslé 2001; Zhao and Kinfu 2005; Zhao 2011) and Latin America (Palloni and Pinto-Aguirre 2011) in 1950-2000. We expect that some countries, especially Japan, Hong Kong, Republic of Korea or Singapore, are entering or have already entered the fourth stage of health transition that is characterized by declining cardiovascular mortality, ageing, lifestyle modification, emerging and resurgent diseases (Omran 1998).

\section{Links between mortality and socioeconomic developments}

What are the underlying forces behind the changes in old age mortality in the last three decades in Eastern and South-Eastern Asian countries? This is certainly a challenging question that is beyond the scope of the present study. We hereby attempted to examine the simple associations between some basic socioeconomic factors and the overall level of old age mortality indexed by life expectancy at age 65 and the age standardized cause-specific death rates as presented earlier using time series data from 1980-1985 to 2005-2010. The basic socioeconomic indicators were measured by proxies consisting of expected years of schooling (human capital environment), GDP per capita, and urbanization. ${ }^{14}$ These three major factors have been persistently proven to be powerful predictors of life expectancy at birth (e.g., Lin et al. 2012; Rogers and Wofford 1989).

\footnotetext{
${ }^{14}$ The expected years of schooling means the number of years of schooling that a child of school entrance age (under age 7) can expect to receive if prevailing patterns of age-specific enrolment rates persist throughout the child's lifetime. This indicator is sex-specific. GDP per capita is measured in purchasing power parity US\$ terms at constant 2005 price. These two variables were directly retrieved from the 2011 Revision of the International Human Development Indicators database hosted by the United Nations Development Program (UNDP 2011). Urbanization is measured by percentage share of urban population out of the total population for a given country, which was from the 2011 Revision of the World Urbanization Prospects (United Nations Population Division 2012). Out of fourteen countries in Table 1, two countries (i.e., DPR Korea and Lao PDR) do not have sufficient data on socioeconomic development, leaving twelve countries in the analyses of $\mathrm{e}_{65}$. Because some countries do not have empirical data for all six periods from 1980-1985 to 2005-2010, the number of observations in our models for $\mathrm{e}_{65}$ was only sixty-five. The number of empirical data points was further reduced to only twenty-three in modeling cause-specific death rates from the five countries analyzed above. We checked the collinearity to ensure the value of the variance inflation factor (VIF) of each of the three variables less than 10 in the linear regressions (e.g., Hair et al. 2009).The nonlinear associations between socioeconomic development indicators and mortality at old ages were further checked and modeled by including the quadratic terms of these three variables. In our final statistical models, however, we excluded the quadratic term of expected years of schooling because it was not significant. Because of the structure of our data, linear regressions with panel-corrected standard errors (-xtpcse-) were employed in our analyses to ensure
} 
Table 3 shows that more than three-fourths of the variations in life expectancy at age 65 for countries in Eastern and South-Eastern Asia between 1980 and 2010 could be explained by these three socioeconomic variables, implying that these factors had strong associations with the overall level of mortality in the elderly populations (i.e., $\mathrm{e}_{65}$ ) in the region. Specially, a positive and significant association between $\mathrm{e}_{65}$ and GDP per capita was found for both men and women. This may explain to some extent why there was a greater gain in $\mathrm{e}_{65}$ and a greater reduction in mortality in countries in Eastern Asia in the study period as compared to South-Eastern Asia, and why China had a smaller gain in $\mathrm{e}_{65}$ than Japan, Hong Kong, and Republic Korea in Eastern Asia. However, such a positive association tended to diminish when GDP per capita went up (because the squared term was significant and its sign was negative). In other words, at some point in the future, greater gains in $e_{65}$ would be seen in less rich countries. These results are in line with the classic link between economic growth and mortality or life expectancy at birth (also called the Preston curve) (Cutler, Deaton, and Lleras-Muney 2006; Tapia Granados 2012; Preston 1975; Pritchett and Viarengo 2010). It has been assumed that economic growth could affect life expectancy either directly, through improving material living conditions, or indirectly, through facilitating advances in medical technology, raising educational levels, improving food security and sanitation and infrastructure, developing social welfare systems, and reducing poverty (Janssen, Kunst and Mackenbach 2006). The diminishing effects of economic growth on improvement of life expectancy and reduction of cause-specific mortality is also possibly because these five countries are relatively economically well off in the region, and because they have reached the third or fourth stage of the health transition and thus mortality is more associated with health-related risk behavior as we also noted earlier (Omran 1998). Some scholars argue that the high improvement in life expectancy in the Japanese elderly population was likely to be attributable to individual healthy behaviors and lifestyles, such as healthy diets, regular exercise, high community participation, in addition to a good nationwide healthcare system, good family relations and filial piety tradition, medical advancement, and high income (Ikeda et al. 2011; Rogers and Crimmins 2011).

Our results further revealed that the number of expected years of schooling (human capital environment) was positively associated with life expectancy at age 65 for both sexes, with a stronger effect found in women. Literature has persistently shown that higher education or human capital investment that improve health literacy and other knowledge are equally or even more important than economic growth in determining the overall health or mortality of a society (Muller 2002). It is possible that the educational improvement in women improves their health awareness more than it does for men and it

the standard errors to be robust to each country having a different variance of the disturbances and to each country's observations being correlated with those of other countries through time (see Stata 2011:379-383). This approach is one form of multilevel analysis with fixed effects for each country. 
also enables them to have more resources to invest in their health, as compared to men with less education or none at all (Filmer and Pritchett 1999; Harper, Lynch, and Davey Smith 2011; Pritchett and Viarengo 2010). A high level of educational attainment in a society may also mean that the government has greatly developed public health projects and social welfare programs that are directly linked with the health improvement of its citizens.

Table 3: $\quad$ Linear regression coefficients between old age mortality and socioeconomic development indicators from 1980-1985 to 2005-2010 for selected Eastern and South-Eastern Asian countries

\begin{tabular}{|c|c|c|c|c|c|c|c|c|}
\hline & \multicolumn{8}{|c|}{ Causes of death $\left({ }^{*} 1000\right)$} \\
\hline & $\mathrm{e}_{65}$ (years) & Stroke & $\begin{array}{c}\text { Heart } \\
\text { diseases }\end{array}$ & Cancers & Diabetes & $\begin{array}{l}\text { Respiratory } \\
\text { diseases }\end{array}$ & $\begin{array}{l}\text { Infectious } \\
\text { diseases }\end{array}$ & $\begin{array}{l}\text { All other } \\
\text { causes }\end{array}$ \\
\hline \multicolumn{9}{|l|}{ Women } \\
\hline $\begin{array}{l}\text { Expected years of } \\
\text { schooling of children }\end{array}$ & $0.580 * * *$ & 0.004 & $-1.061 \star \star * *$ & $-0.688^{\star \star \star}$ & $0.350^{* * *}$ & $-0.752 * \star \star$ & 0.046 * & 2.024 *** \\
\hline GDP per capita (US\$) & $0.439 * * *$ & $-0.468 * * *$ & $-0.269 *$ & $0.170+$ & $-0.116+$ & -0.003 & -0.020 & $-1.717^{\star \star \star}$ \\
\hline $\begin{array}{l}\text { GDP per capita } \\
\text { squared }\end{array}$ & $-0.006 * * *$ & 0.006 ** & $0.005+$ & -0.002 & 0.002 & 0.001 & -0.000 & $0.021^{* \star \star}$ \\
\hline $\begin{array}{l}\text { Urban proportion } \\
\left({ }^{*} 100\right)\end{array}$ & $-0.238 * *$ & -0.013 & 0.275 ** & -0.013 & $-0.052 * \star *$ & $-0.647^{* * *}$ & $-0.022+$ & $0.828^{* \star *}$ \\
\hline $\begin{array}{l}\text { Urban proportion } \\
\text { squared }\end{array}$ & $0.001 * *$ & -0.000 & $-0.002 * *$ & 0.000 & 0.0004 ** & $0.004^{* * *}$ & $0.0003^{* *}$ & $-0.005^{* * *}$ \\
\hline $\begin{array}{l}\text { \# of observations } \\
\text { (countries) }\end{array}$ & $65(12)$ & $23(5)$ & $23(5)$ & $23(5)$ & $23(5)$ & $23(5)$ & $23(5)$ & $23(5)$ \\
\hline $\mathrm{R}^{2}$ & 0.76 & 0.95 & 0.83 & 0.76 & 0.48 & 0.97 & 0.84 & 0.82 \\
\hline \multicolumn{9}{|l|}{ Men } \\
\hline $\begin{array}{l}\text { Expected years of } \\
\text { schooling of children }\end{array}$ & 0.210 *** & 0.234 ** & $-1.701 * * *$ & -0.175 & $0.465^{* \star *}$ & $-1.135^{* * *}$ & 0.134 ** & 2.662 *** \\
\hline GDP per capita (US\$) & $0.426 * * *$ & $-0.727^{\star * *}$ & $-0.560 * \star *$ & 0.264 & $-0.135+$ & 0.143 & $-0.121^{\star \star \star}$ & -2.691 *** \\
\hline $\begin{array}{l}\text { GDP per capita } \\
\text { squared }\end{array}$ & $-0.005 * *$ & $0.009^{* * *}$ & 0.010 ** & $-0.005+$ & 0.002 & -0.003 & 0.001 ** & $0.035^{* * *}$ \\
\hline $\begin{array}{l}\text { Urban proportion } \\
\left({ }^{*} 100\right)\end{array}$ & $-0.121 * * *$ & 0.078 & $0.662 * \star *$ & -0.067 & $-0.048^{* *}$ & $-0.844 * * *$ & 0.029 & $1.536^{* \star *}$ \\
\hline $\begin{array}{l}\text { Urban proportion } \\
\text { squared }\end{array}$ & 0.001 * & -0.001 & $-0.004^{* * *}$ & 0.001 & $0.0004^{* * *}$ & $0.006^{* * *}$ & 0.000 & $-0.009 * * *$ \\
\hline $\begin{array}{l}\text { \# of observations } \\
\text { (countries) }\end{array}$ & $65(12)$ & $23(5)$ & $23(5)$ & $23(5)$ & $23(5)$ & $23(5)$ & $23(5)$ & $23(5)$ \\
\hline $\mathrm{R}^{2}$ & 0.81 & 0.96 & 0.80 & 0.58 & 0.63 & 0.94 & 0.89 & 0.78 \\
\hline
\end{tabular}

Note: GDP per capita was in purchasing power parity US\$ ( $\left.{ }^{*} 1000\right)$ (at constant 2005 price). In cause-specific death regressions, only five countries with available data were included. In the regressions, causes of death were inflated by 1000 . Cause-specific death rates referred to the entire elderly population aged 65 or older by sex using age standardized rates as indicated in Section 3.1.

Sources: Life expectancies at age 65 were from United Nations Population Division (2013); urban proportion was from United Nations Population Division (2012); cause-specific death rates were from WHO (2011), indicators of expected years of schooling and GDP per capita were from UNDP (2011).

$+\mathrm{p}<0.1 ;{ }^{*} \mathrm{p}<0.05 ;{ }^{* *} \mathrm{p}<0.01 ;{ }^{* * *} \mathrm{p}<0.001$. 
There was a positive association between the growth of urbanization and $\mathrm{e}_{65}$ without controlling for GDP per capita and education (not shown). However, urbanization tended to have a negative association with $\mathrm{e}_{65}$ when GDP per capita and the educational level were taken into consideration. Research showed that although urbanization contributes significantly to economic growth, it has also linked with environmental degradation, urban poverty, social inequity, housing shortage, unhealthy lifestyles, crime, and other social problems that are unfavorable to human health and wellness, especially when the urban proportion is below 70\% (Stephen 1995; Weiss 2001). The results in Table 3 further reveal that such a negative effect tends to be reduced once urbanization reaches a certain high level. The negative impact of the urbanization process on health and mortality in the existing literature is inadequately studied. Further research on this topic is clearly warranted.

Overall, gains in $\mathrm{e}_{65}$ during the period 1980 to 2010 in Eastern and South-Eastern Asia were accordance with its socioeconomic development and urbanization process. This is because economic development is a major driving force behind better living standards, better living and working environments, sufficient nutritional intake, and better availability of and accessibility to health care, that are attributable to the reduction in old age mortality (Zhao 2011). Of course, various other factors such as certain social practices and traditions, income equity, health awareness and knowledge, and risk-preventing behavior have also likely played a certain role in mortality reduction (Zhao 2011). Studies in other developing countries such as in Latin America suggest that economic growth plays an important role in explaining the variation of mortality, but years of schooling is always a potent driver of change (Palloni and Pinto-Aguirre 2011).

With regard to the cause-specific models, in most cases of age-standardized cause-specific mortality rates, the socioeconomic factors explained a similar or larger portion of variations as compared to what they did for $\mathrm{e}_{65}$, which could be either due to small sample size or because of stronger associations between socioeconomic factors and cause-specific mortality rates in these five countries. According to our results, the higher level of GDP per capita was consistently associated with a lower mortality rate from circulatory diseases (stroke and heart diseases). However, the association usually tended to diminish when GDP per capita reaches a certain level, which is similar to the association between economic growth and the overall mortality at old ages $\left(\mathrm{e}_{65}\right)$ as we noted earlier.

The association between economic growth and mortality from diabetes, cancer, and respiratory diseases (including pneumonia) was either weak or insignificant. There is evidence showing that some type of cancers such as lung cancer, colon cancer, and liver cancer among both males and females, and breast cancer among females did not change much, or even increased, from 1980 to 2000 in Japan (Ysohinaga and Une 2005). Such an increase is also observed in the U.S. in the 2000s (Manton, Akushevich, and 
Kravchenko 2009; National Center for Health Statistics 2011) and in some European countries (Levi et al. 2001), although cancer mortality exhibited a decline in the 1980s and 1990s in these Western societies. Studies have shown that the shift in health behaviors was to some degree responsible for the increase or the stagnation of decline in cancer mortality (Ott et al. 2011).

There was no clear pattern for the association between cause-specific deaths and education and urbanization in our analyses. More education in a country was associated with lower levels of mortality due to respiratory diseases for both men and women. Yet a higher national level of years of schooling was associated with a higher level of risk of death from diabetes and infectious diseases for both sexes when economic development level and urbanization were taken into account. The positive associations are likely to be because China's educational level is relatively low, and it has a lower mortality from these two causes than the other four countries in which educational level is usually high. Because the explained variation for mortality from diabetes is not very large, we speculate that some important factors are missing. Analyses including behavioral factors are desirable.

Although the growth of urbanization is negatively associated with mortality due to respiratory disease and diabetes, the mortality from heart diseases is likely to increase in the process of urbanization. Literature has indicated that urbanization has altered individuals' behavior associated with deleterious diet habits, less physical activity and tobacco addiction, which leads to an increased risk of heart diseases (Reddy 2002).

The portion of variance explained in deaths from cancers and diabetes by these three factors was relatively smaller than that of other causes, leaving some room for additional explanations. Recent developments in prospective genetic treatment of some types of cancers would eventually lead to new preventive strategies, targeted screening or effective treatment schemes for cancer, that eventually lower cancer mortality (Sahyoun et al. 2001). Furthermore, it has been well established that smoking is a major risk factor for certain types of cancers and cardiovascular diseases. For example, Himes (2011) finds that cigarette smoking is the single-most preventable cause of death in the developed world and a major factor in the less developed countries. Christensen and his colleagues (2010) conclude that smoking and alcohol-related deaths accounted for virtually all of the disparity in life expectancy between Denmark and Sweden in 1997-2001, with smoking playing a larger role. Yet it remains a serious health problem in many Eastern and South-Eastern Asian countries. According to the latest estimates made by the WHO (2009), with exceptions for adult men in Singapore (25\%) and Thailand (37\%), more than $40 \%$ of adult males are smokers in all other countries examined in this study: China (57\%), DPR Korea (60\%), Republic of Korea (53\%), Indonesia (47\%), Japan (40\%), the Lao PDR (66\%), Malaysia (54\%), Myanmar (49\%), Mongolia (48\%), the Republic of Korea (53\%), the Philippines (58\%), and Viet Nam (49\%). In addition, 
studies from developed countries have shown that male mortality has been much more heavily influenced by smoking than female mortality (Preston, Glei, and Wilmoth 2010). No wonder some scholars argue that many deaths in Asia are behavior-related and therefore could be prevented with sufficient public and individual efforts (e.g., Zhao 2011:148). Nevertheless, we argue that the negative contributors of these risk behaviors are much smaller than those positive contributors in the study period, so that the overall trend of old age mortality continues to decline in most countries in the region.

\section{Concluding remarks}

The study examined the trends in old age mortality, their age and sex differentials and trends in cause-specific mortality. While mortality transitions in these populations took place in different times, under different political systems and at different levels of socioeconomic development and living environment, changes in age patterns and sex differentials in mortality showed certain regularities. The evidence provided in this study shows that as far as sex differentials in mortality were concerned, there was a notable division between some Asian populations. Our study demonstrated that many Eastern and South-Eastern Asian countries made a significant progress in improving health and lowering mortality among older adults in the past several decades. Their successful experiences not only provide further support to the theories of the demographic and epidemiological transitions, but also offer new lessons and insights that could greatly enrich our knowledge of these changes. Through decomposing changes in life expectancy at age 65 by age, sex and major causes of death for five countries in the region, the study also likely shed light on the relationship between epidemiological transition, changing age patterns of mortality, and improving life expectancy in these populations.

The change in $\mathrm{e}_{65}$ over time in Eastern and South-Eastern Asia suggests that there is still much room for further reductions in old age mortality, even though $\mathrm{e}_{65}$ in some of these populations exhibit the highest levels in the world, which possibly supports the notion of unstoppable increase in human life expectancy in the foreseeable future (Oeppen and Vaupel 2002). The trends in old age mortality will likely be the driving force in changes of overall life expectancy in this region, although forecasting mortality after age 65 is challenging (Favero and Giacoletti 2011). Once infectious diseases have been eliminated or brought to a very low level, overall progress in health depends on economic and social progress, public health regimes, and broader cultural changes that modify unhealthy behaviors and lifestyles (Vallin and Meslé 2001; Glei, Meslé, and Vallin 2010). It has been argued that these factors are powerful enough to create mortality gaps among countries experiencing different political and economic trends (Caselli and 
Vallin 2006). It could be important to see when populations from other countries in the region reach the levels of life expectancy of Japan, which countries are in the vanguard of increased life expectancy, and what factors are responsible for progress. Another important issue concerning future trends is mortalities due to cancer and diabetes in China and Republic of Korea. Will these trends toward decreasing life expectancy continue, or will they start to increase their life expectancy as Japan, Hong Kong, and Singapore have done?

It is worth noting that during the epidemiological transition substantial changes in major health risk factors and strategies of risk prevention occur. When mortality is high, improvements of healthcare system are necessary. Yet when old age mortality falls to moderate or low levels, further increase in $\mathrm{e}_{65}$ does not depend merely on the healthcare system; it also depends on a variety of personal features that affect an individual's health behaviors, such as diet, exercise, cigarette smoking, and compliance with medical protocols (Preston and Ho 2009). Our findings thus have some implications. In some high-mortality countries, expansion of social security, public health campaigns and implementation of other health programs are required in the future; whereas in low mortality countries, investment in sophisticated medical technology and long-term or even lifetime treatment are usually required to further lower mortality caused by cancers, cardiovascular disease, and other degenerative diseases (Zhao 2011).

Caution is needed, however, when readers interpret the results, due to the several limitations of this study. First, we did not include data before 1980 for any countries or areas because of concerns about data quality and reliability (although with exceptions for Japan and possibly Hong Kong) as well as the constraints imposed by data availability. This design prohibits us from examining the general trend over a relatively longer period, which may likely be more informative. But we believe that the poor data quality could introduce substantial biases, undermine the underlying trajectory, and thus lead to wrong conclusions. Second, we only analyzed causes of death for five countries in the region from 1980 to 2010 because no reliable data from other countries in the two regions would allow us to disentangle the roles played by different causes of death from 1980 to 2010 . In spite of this, we still believe that the cause-specific death data in these five countries highlighted some major changes in old ages mortality and their variations in Eastern and South-Eastern Asia countries in recent decades. Nevertheless, we are aware that most of the nations in the region not analyzed are experiencing rapid population aging and urbanization before they become rich, which is dissimilar to developed countries, where population aging and urbanization usually occurred in prosperous economies. Thus, the associations between socioeconomic development factors and causes of death may differ from what we analyzed for these five countries. Rapid globalization may also alter the established associations between socioeconomic development and mortality and causes of death (Harper and Armelagos 2010). We welcome more research on this theme based 
on time series data from more countries with a relatively long period. Third, because of possible under-reporting of death and the low proportion of causes of death with medical certification and diagnoses are known to be common issues in many developing countries, the distribution of causes of death for countries under study could have some biases. Furthermore, medical advancements that enable medical professionals to accurately identify primary causes of death, changes in the criteria of classification of causes of death, and changes in proportion of ill-defined causes of deaths over time may introduce some biases in classifying the causes of death, which would affect the data compatibility across periods. Yet such biases are likely to have limited impact on the general trend of changes of the distribution of causes. Fourth, the results of associations between socioeconomic development and old-age mortality presented in the study are rather crude, especially for causes-specific death rates in that we only included five countries with very few data points in time series in the analyses due to unavailability of data. Furthermore, a growing body of evidence has suggested that individual social, behavioral, and genetic factors and their interactions are important associates or determinants of health and mortality (Hernandez and Blazer 2006), as well as neighborhood environments (Kawachi and Berkman 2003). As more micro-level longitudinal datasets consisting of these factors are becoming available in the region (National Institute on Aging 2011), comprehensive studies integrating these factors under a multilevel framework are clearly warranted. At the country level, we did find data on the prevalence of obesity, the prevalence of smoking, and pension coverage. However, we did not include these data in our statistical analyses because they are only available for the most recent period, and are not available for some countries in the region. Global effort in collecting time series data on risk behaviors at the country or sub-national levels is necessary. Fifth, studies have shown that health conditions among several elderly populations in the region is getting worse, in spite of prolonged longevity (Cheung and Yip 2010; Ofstedal et al. 2007). Yet we are unable to examine possible trajectories of health expectancies (Robine and Michel 2004) primarily because of space limitations and lack of nationwide data.

In spite of these limitations, this paper makes a valuable contribution to the existing literature by providing a general overview of the trends of old age mortality in Eastern and South-Eastern Asian countries that we do not know much about. Our findings could be informative for understanding of health transition as well as for policy-formulation on population aging. 


\section{Acknowledgements}

The authors would like to thank Professor Jessica Sautter from University of the Sciences in Philadelphia, Pennsylvania; Mr. François Pelletier, Chief, Population Estimates and Projections Section, Population Division, DESA, United Nations; the Associate Editor of this journal, and two anonymous reviewers, for their helpful comments. 


\section{References}

Beltran-Sanchez, H., Preston, S.H., and Canudas-Romo, V. (2008). An integrated approach to cause-of-death analysis: Cause-deleted life tables and decompositions of life expectancy. Demographic Research 19(35): 1323-1350. doi:10.4054/DemRes.2008.19.35.

Bongaarts, J. (2009). Human population growth and the demographic transition. Philosophical Transactions of the Royal Society B: Biological Sciences 364(1532): 2985-2990. doi:10.1098/rstb.2009.0137.

Caselli, G. and Vallin, J. (2006). Geographical variations of mortality. In: Caselli, G., Vallin, J., and Wunsch, G. (eds.). Demography: Analysis and synthesis, Volume II. London: Academic Press: 207-234.

Cheung, K.S.L. and Yip, P.S.F. (2010). Trends in healthy life expectancy in Hong Kong SAR 1996-2008. European Journal of Ageing 7(4): 257-269. doi:10.1007/s1043 3-010-0171-3.

Choi, Y. and You, D. (2004). Adult mortality in East Asia: Trends and patterns. Paper presented at the Adult Mortality in Developing Countries. Marconi Center, CA, July 9, 2004.

Christensen, K., Davidsen M., Juel, K., Mortensen, L., Rau, R., and Vaupel, J.W. (2011). The divergent life expectancy trends in Denmark and Sweden- and some potential explanations. In: Crimmins, E.M., Preston, S.H., and Cohen, B. (eds.): International Differences in Mortality at Older Ages: Dimensions and Source. Washington, D.C.: The National Academies Press: 385-407.

Coale, A.J. and Kisker, E.E. (1986). Mortality crossovers: Reality or bad data? Population Studies 40(3):389-401. doi:10.1080/0032472031000142316.

Crimmins, E.M., Preston, S.H., and Cohen, B. (eds.) (2011). International Differences in Mortality at Older Ages: Dimensions and Sources. Washington, DC: The National Academies Press.

Crimmins, E.M., Preston, S.H., and Cohen, B. (2011). Introduction and overview. In Crimmins, E.M., Preston, S.H., and Cohen, B. (eds.): International Differences in Mortality at Older Ages: Dimensions and Source. Washington, D.C.: The National Academies Press: 1-13.

Cutler, D., Deaton, A., and Lleras-Muney, A. (2006). The determinants of mortality. Journal of Economic Perspectives 20(3): 97-120. doi:10.1257/jep.20.3.97. 
Favero, C.A. and Giacoletti, M. (2011). Progress in medicine, limits to life and forecasting mortality. Milano, Italy: CEPR, NBER and Università Bocconi (Working Paper No. 406).

Filmer, D. and Pritchett, L. (1999). The impact of public spending on health: Does money matter? Social Science and Medicine 49(10): 1309-1323. doi:10.1016/S0277-95 36(99)00150-1.

Glei, D.A., Meslé, F., and Vallin, J. (2011). Diverging trends in life expectancy at age 50: A look at causes of death. In: Crimmins, E.M., Preston, S.H., and Cohen, B. (eds.): International Differences in Mortality at Older Ages: Dimensions and Source. Washington, D.C.: The National Academies Press: 17-67.

Gómez-Redondo, R. and Boe, C. (2005). Decomposition analysis of Spanish life expectancy at birth: Evolution and changes in the components by sex and age. Demographic Research 13(4): 521-546. doi:10.4054/DemRes.2005.13.20.

Goodkind, D. (2011). Child underreporting, fertility, and sex ratio imbalance in China. Demography 48(1): 291-316. doi:10.1007/s13524-010-0007-y.

Hair, J., Black, W.C., Babin, B.J., and Anderson, R.E. (2009). Multivariate data analysis, 7th Edition. Prentice Hall.

Harper, K. and Armelagos, G. (2010). The changing disease-scape in the third epidemiological transition. International Journal of Environment Research and Public Health 7(2): 675-697. doi:10.3390/ijerph7020675.

Harper, S., Lynch, J., and Smith, G.D. (2011). Social determinants and the decline of cardiovascular diseases: Understanding the links. Annual Review of Public Health 32(1): 39-69. doi:10.1146/annurev-publhealth-031210-101234.

He, J., Gu, D., Wu, X., Reynolds, K., Duan X. et. al. (2005). Major causes of death among men and women in China. The New England Journal of Medicine 353(11): 1124-1134. doi:10.1056/NEJMsa050467.

Hernandez, L.M. and Blazer, D.G. (eds.) (2006). Gene, behavior, and social environment: Moving beyond the nature/nurture debate. Washington, DC: The National Academic Press.

Himes, C.L. (2011). Relationships among health behaviors, health, and mortality. In: Rogers, R.G. and Crimmins, E.M. (eds.) (2011). International Handbook of Adult Mortality. New York: Springer Publisher: 289-310. doi:10.1007/978-90-481-9 996-9. 
Hufana, L., Cajita, J., Morante, L., Lopez, J., Tan, C., Mikkelsen, L., and Aung, E. (2009). Assessing the production, quality and use of national vital statistics: a case study of the Philippines. Queensland: University of Queensland.

Hummer, R.A., Rogers, R.G., Masters, R. K., and Saint Onge, J.M. (2009). Mortality patterns in late life. In: Uhlenberg, P. (ed.). International Handbook of Population Aging. Springer Netherlands: 521-542. doi:10.1007/978-1-4020-83 56-3_23.

Ikeda, N., Saito, E., Kondo, N., Inoue, M., Ikeda, S., Satoh, T. et al. (2011). What has made the population of Japan healthy? The Lancet 378(9796): 1094-1105. doi:10.1016/S0140-6736(11)61055-6.

Janssen, F., Kunst, A.E., and Mackenbach, J.P. (2006). Association between gross domestic product throughout the life course and old-age mortality across birth cohorts: Parallel analyses of seven European countries, 1950-1999. Social Science \& Medicine 63(1): 239-254. doi:10.1016/j.socscimed.2005.11.040.

Janssen, F., Mackenbach, J.P., and Kunst, A.E. (2004). Trends in old-age mortality in seven European countries, 1950-1999. Journal of Clinical Epidemiology 57(2): 203-216. doi:10.1016/j.jclinepi.2003.07.005.

Janssen, F., Kunst, A.E., and Mackenbach, J.P. (2007). Variations in the pace of old-age mortality decline in seven European countries, 1950-1999: The role of smoking and other factors earlier in life. European Journal of Population 23(2): 171-188. doi:10.1007/s10680-007-9119-5.

Kawachi, I. and Berkman, L.F. (eds.) (2003). Neighborhoods and Health. New York: Oxford University Press. doi:10.1093/acprof:oso/9780195138382.001.0001.

Klenk, J., Rapp, K., Buchele, G., Keil, U., and Weiland, S.K. (2007). Increasing life expectancy in Germany: quantitative contributions from changes in age- and disease-specific mortality. European Journal of Public Health 17(6): 578-592. doi:10.1093/eurpub/ckm024.

Knodel, J. and Chayovan, N. (1991). Age and birth date reporting in Thailand. Asian and Pacific Population Forum 5(2-3): 41-50, 64-76.

Lee, J.S. (2012). Child obesity in South Korea and possible solutions. International Proceedings of Economics Development and Research 53(17): 77-80.

Levi, F., Lucchini, F., Negri, E., Boyle, P., and La Vecchia, C. (2001). Changed trends of cancer mortality in the elderly. Annals of Oncology 12(10): 1467-1477. doi:10.1023/A:1012539213643. 
Lin, R-T., Chen, Y-M, Chien, L-C., and Chan, C-C. (2012). Political and social determinants of life expectancy in less developed countries: A longitudinal study. BMC Public Health 12(1): 1-8. doi:10.1186/1471-2458-12-85.

Lopez, A.D. (1984). Sex differentials in mortality. WHO Chronicle 38(5): 217-224.

Luy, M., Wegner, C., and Lutz, W. (2011). Adult mortality in Europe. In: Rogers, R.G. and Crimmins, E.M. (eds.) (2011). International Handbook of Adult Mortality. New York: Springer Publisher: 49-81. doi:10.1007/978-90-481-9996-9.

Mackenbach, J. and Garssen, J. (2011). Renewed progress in life expectancy: The case of the Netherlands. In: Crimmins, E.M., Preston, S.H., and Cohen, B. (eds.): International Differences in Mortality at Older Ages: Dimensions and Source. Washington, D.C.: The National Academies Press: 369-384.

Manton, K.G., Akushevich, I., and Kravchenko, J. (2009). Cancer mortality and morbidity patterns in the U.S. population. New York: Springer. doi:10.1007/978 $-0-387-78193-8$.

Mathers, C.D. (2005). Uncertainty and data availability for the global burden of disease estimates 2000-2002. Geneva: World Health Organization.

McNicoll, G. (2006). Policy Lessons of the East Asian demographic transition. Population and Development Review 32(1): 1-25. doi:10.1111/j.1728-4457.2006. 00103.x .

Merli, M.G. (1998). Mortality in Vietnam, 1979-1989. Demography 35(3): 345-360. doi: $10.2307 / 3004042$.

Meslé, F. and Vallin, J. (2011). Historical trends in mortality. In Rogers, R.G. and Crimmins, E.M. (eds.) (2011). International Handbook of Adult Mortality. New York: Springer Publisher: 9-47. doi:10.1007/978-90-481-9996-9.

Mladovsky, P., Allin, S., Masseria, C., Hernandez-Quevedo, C., McDaid, D., and Mossialos, E. (eds.) (2009). Health in the European Union: Trends and analysis. World Health Organization.

Muller, A. (2002). Education, income inequality, and mortality: a multiple regression analysis. British Medical Journal 324(7328): 23-25. doi:10.1136/bmj.324.7328. 23.

National Center for Health Statistics. (2011). Health, United States, 2010: With special feature on death and dying. Hyattsville, MD. 
Gu et al.: Old age mortality in Eastern and South-Eastern Asia

National Institute on Aging (2011). Publicly Available Databases for Aging-Related Secondary Analyses in the Behavioral and Social Sciences. Bethesda, MD.

Oeppen, J. and Vaupel, J.W. (2002). Broken limits to life expectancy. Science 296(5570): 1029-1031. doi:10.1126/science.1069675.

Ofstedal, M., Zimmer, Z., Hermalin, A.I., Chan, A., Chuang, Y-L., Natividad, J., and Tang, Z. (2007). Short-term trends in functional limitation and disability among older Asians: A comparison of five Asian settings. Journal of Cross-Cultural Gerontology 22(3): 243-261. doi:10.1007/s10823-006-9025-z.

Olshansky, J.S., and Ault, A.B. (1986). The fourth stage of the epidemiologic transition: The age of delayed degenerative disease. Milbank Quarterly 64(3): 355-391. doi:10.2307/3350025.

Omran, A.R. (1971). The epidemiologic transition: A theory of the epidemiology of population change. Milbank Memorial Fund Quarterly 49(4): 509-538. doi:10.2307/3349375.

Omran, A.R. (1998). The epidemiologic transition theory revisited thirty years later. World Health Statistics Quarterly 51: 99-119.

Ott, J.J., Ullrich, A., Mascarenhas, M., and Stevens, G.A. (2011). Global cancer incidence and mortality caused by behavior and infection. Journal of Public Health 33(2): 223-233. doi:10.1093/pubmed/fdq076.

Palloni, A. and Pinto-Aguirre, G. (2011). Adult mortality in Latin America and the Caribbean. In: Rogers, R.G. and Crimmins, E.M. (eds.) (2011). International Handbook of Adult Mortality, New York: Springer Publisher: 114-132. doi:10.1007/978-90-481-9996-9.

Pollard, J.H. (1982). The expectation of life and its relationship to mortality. Journal of Institute of Actuaries 109(02): 225-240. doi:10.1017/S0020268100036258.

Popkin, B.M., Horton, S., and Kim, S. (2001). The nutritional transition and diet-related Chronic diseases in Asia: Implications for prevention. Washington D.C.: International Food Policy Research Institute (Working paper No. 105).

Preston, S.H. (1975). The changing relation between mortality and level of Economic development. Population Studies 29(2): 231-248. doi:10.2307/2173509. 
Preston, S.H., Glei, D.A., and Wilmoth, J.R. (2011). Contribution of smoking to international differences in life expectancy. In: Crimmins, E.M., Preston, S.H., and Cohen, B. (eds.): International Differences in Mortality at Older Ages: Dimensions and Source. Washington, D.C.: The National Academies Press: 105-131.

Preston, S.H. and Ho, J.Y. (2009). The US health care system and lagging life expectancy: A case study. Philadelphia: Population Studies Center, University of Pennsylvania, PSC Working Paper Series (09-01)

Pritchett, L. and Viarengo, M. (2010). Explaining the cross-national time series variation in life expectancy: Income, women's education, shifts, and what else? New York: United Nations Development Program, Human Development Research Paper (No. 2010/31).

Rajaratnam, J.K., Marcus, J.R., Levin-Rector, A., Chalupka, A.N., Wang, H., Dwyer, L., Costa, M. et al. (2010). Worldwide mortality in men and women aged 15-59 years from 1970 to 2010: A systematic analysis. The Lancet 375(9727): 1704-1720. doi:10.1016/S0140-6736(10)60517-X.

Rao, C., Lopez, A.D., Yang, G., Begg, S., and Ma, J. (2005). Evaluating national cause-of-death statistics: principles and application to the case of China. Bulletin of the World Health Organization 83(8): 618-625.

Reddy, S.K. (2002). Cardiovascular diseases in the developing countries: Dimensions, determinants, dynamics and directions for public health action. Public Health Nutrition 5 (1a): 231-237. doi:10.1079/PHN2001298.

Robine, J.M. (2001). Redefining the stages of the epidemiological transition by a study of the dispersion of life spans: the case of France. Population: An English Selection 13(1): 173-193. doi:10.2307/3030265.

Robine, J.M., and Michel, J.-P. (2004). Looking forward to a general theory on population aging. Journal of Gerontology: Medical Sciences 59(6): 590-597.

Rogers, R.G. and Crimmins, E.M. (eds.) (2011). International Handbook of Adult Mortality. New York: Springer Publisher. doi:10.1007/978-90-481-9996-9.

Rogers, R.G., Everett, B.G., Saint Onge, J.M., and Krueger, P.M. (2010). Social, behavioral, and biological factors and sex differences in mortality. Demography 47(3): 555-578. doi:10.1353/dem.0.0119. 
Rogers, R.G. and Wofford, S. (1989). Life expectancy in less developed countries: socioeconomic development or public health? Journal of Biosocial Science 21(02): 245-252. doi:10.1017/S0021932000017934.

Rukumnuaykit, P. (2006). Mortality and causes of death in Thailand: Evidence from the survey of population change and death registration. Asia-Pacific Population Journal 21(1): 67-84.

Sahyoun, N.R., Lentzner, H., Hoyert, D., and Robinson, K.N. (2001). Trends in causes of death among the elderly. Aging Trends 1:1-10

Staetsky, L. (2009). Diverging trend in female old age mortality: A reappraisal. Demographic Research 21(30): 885-914. doi:10.4054/DemRes.2009.21.30

StataCorp. (2011). Stata longitudinal-data/panel-data reference manual: Release 12.0. College Station, TX: Stata Corporation.

Stephens, C. (1995). The urban environment, poverty and health in developing countries. Health Policy and Planning 10(2): 109-121. doi:10.1093/heapol/10.2.109.

Tapia Granados, J.A. (2012). Economic growth and health progress in England and Wales: 160 years of a changing relation. Social Science \& Medicine 74(5): 688-695. doi:10.1016/j.socscimed.2011.11.019.

United Nations Development Program (2011). International Human Development Indicators [electronic resource].

United Nations Population Division (2012). The World Urbanization Prospects: The 2011 Revision. [electronic resource].

United Nations Population Division. (2013). The World Population Prospects: The 2012 Revision. [electronic resource].

Vallin, J. and Meslé, F. (2001). Trends in mortality in Europe since 1950: Age-, sexand cause-specific mortality. In: Vallin, J., Meslé, F., and Valkonen, T. (eds.) Trends in Mortality and Differential Mortality. Strasbourg. Council of Europe Publishing: $31-186$

Vapattanawong, P. and Prasartkul, P. (2011). Under-registration of deaths in Thailand in 2005-2006: Results of cross-matching data from two sources. Bulletin of the World Health Organization 89(11): 806-812. doi:10.2471/BLT.10.083931. 
Waldron, I. (1983). The role of genetic and biological factors in sex differentials in mortality. In: Lopez, A.D. and Ruzicka, L.T. (eds.). Sex Differentials in Mortality: Trends, Determinants and Consequences. Canberra: Australian National University: 141-164.

Weiss, M. (2001). Productive cities and metropolitan economic strategy. A theme paper presented to the United Nations International Forum on Urban Poverty, Marrakech, Morocco, October 16-19, 2001.

WHO (2008). The top ten causes of death. Geneva: WHO (WHO Fact Sheet No.310).

WHO (2009). WHO Report on the global tobacco epidemic: Implementing smoke-free environments. Geneva: WHO.

WHO (2011). World mortality database. [electronic resource]. http://www.who.int/healthinfo/statistics/mortality/en/index.html

World Bank. (2011). World Bank list of economies. [electronic resource]. http://data.worldbank.org/about/country-classifications/country-and-lending-gro ups

Wu, Y. (2006). Overweight and obesity in China. British Medical Journal 333(7564): 362-363. doi:10.1136/bmj.333.7564.362.

Yoshinaga, K. and Une, H. (2005). Contributions of mortality changes by age group and selected causes of death to the increase in Japanese life expectancy at birth from 1950 to 2000. European Journal of Epidemiology 20(1): 49-57. doi:10.1007/s106 54-004-9557-x.

Zeng, Y. and Gu, D. (2008). Reliability of age reporting among the Chinese oldest-old in the CLHLS data sets. In: Zeng Y., Poston, D., Vlosky, D.A, and Gu, D. (eds.). Healthy Longevity in China. Springer Publisher: 61-78.

Zeng, Y. and Vaupel, J.W. (2003). Oldest-old mortality in China. Demographic Research 8(7): 215-244 doi:10.4054/DemRes.2003.8.7.

Zhao, Z. (2003). On the Far Eastern pattern of mortality. Population Studies 57(2): 131-147. doi:10.1080/0032472032000097065.

Zhao, Z. (2004). The Far Eastern pattern of mortality is not a unique regional mortality model: A reply to Noreen Goldman. Population Studies 58(1): 121-124. doi:10.1080/0032472032000175455. 
Gu et al.: Old age mortality in Eastern and South-Eastern Asia

Zhao, Z. (2011). Adult mortality in Asia. In: Rogers, R.G. and Crimmins, E.M. (eds.) (2011). International Handbook of Adult Mortality. New York: Springer Publisher: 133-150. doi:10.1007/978-90-481-9996-9.

Zhao, Z. and Kinfu, Y. (2005). Mortality transition in East Asia. Asian Population Studies 1(1): 3-30. doi:10.1080/17441730500124626. 


\section{Appendices}

Table A-1: Estimated coverage of cause-of-death in WHO mortality database for period 1990 to 2010

\begin{tabular}{lcccc}
\hline Country & $\mathbf{1 9 9 0 - 1 9 9 4}$ & $\mathbf{1 9 9 5 - 1 9 9 9}$ & $\mathbf{2 0 0 0 - 2 0 0 4}$ & $\mathbf{2 0 0 5 - 2 0 0 9}$ \\
\hline China & $<10$ & $<10$ & $<10$ & NA \\
Hong Kong SAR & NA & NA & NA & NA \\
Japan & 100 & 99 & 99 & 100 \\
Republic of Korea & 85 & 98 & 98 & 97 \\
Singapore & 94 & 85 & 78 & 72 \\
\hline
\end{tabular}

Note: In the 2011 version of the WHO mortality database, no coverage information for Hong Kong SAR was available and no cause-specific data were available for China after 2000.

Source: WHO (2011).

Table B-1: Codes for versions of 9 and 10 for the International Classification of Diseases (ICD)

\begin{tabular}{|c|c|c|c|c|}
\hline $\begin{array}{l}\text { Broad Causes of } \\
\text { Death }\end{array}$ & ICD-9 & ICD-9B* & ICD-9 for China & ICD-10 \\
\hline Stroke & $430-438$ & B29 & $\mathrm{C} 051$ & $160-169$ \\
\hline Heart disease & $\begin{array}{l}190-398 \\
402,404-429\end{array}$ & B25, В260, В27-В27 & $\mathrm{C} 043$ & $\begin{array}{l}100-109,|111,| 13, \\
\mid 20-151\end{array}$ \\
\hline Cancer & $140-209$ & B08-B14 & $\mathrm{C} 021$ & $\mathrm{C} 00-\mathrm{C} 97$ \\
\hline Diabetes & 250 & B191 & C035 & E10-E14 \\
\hline $\begin{array}{l}\text { All respiratory } \\
\text { diseases }\end{array}$ & $460-519$ & B31-B32 & $\begin{array}{l}\text { C007-C009, } \\
\text { C052 }\end{array}$ & J00-J99 \\
\hline $\begin{array}{l}\text { All infectious } \\
\text { diseases }\end{array}$ & $\begin{array}{l}\text { 001-139, } \\
680-686\end{array}$ & B01-B06, B420 & $\begin{array}{l}\text { C004-C006, } \\
\text { C018, C069 }\end{array}$ & $\begin{array}{l}\text { A00-A99, } \\
\text { B00-B99, } \\
\text { L00-L089 }\end{array}$ \\
\hline All others & All other codes & All other codes & All other codes & All other codes \\
\hline $\begin{array}{l}\text { Countries and } \\
\text { years }\end{array}$ & & $\begin{array}{l}\text { Hong Kong } \\
(1980-2000), \\
\text { Japan (1980-1994), } \\
\text { Republic of Korea } \\
\text { (1985-1994), } \\
\text { Singapore(1980-2006) }\end{array}$ & $\begin{array}{l}\text { China } \\
(1987-2000)\end{array}$ & $\begin{array}{l}\text { Hong Kong } \\
\text { (2001-2009), } \\
\text { Japan } \\
\text { (1995-2009), } \\
\text { Republic of Korea } \\
(1995-2006)\end{array}$ \\
\hline
\end{tabular}

Note: *, Basic list. Sources: WHO (2011). 
Gu et al.: Old age mortality in Eastern and South-Eastern Asia

Figure C-1: Comparison of age-sex-specific all-cause of death rates between the WPP and WHO

a. China

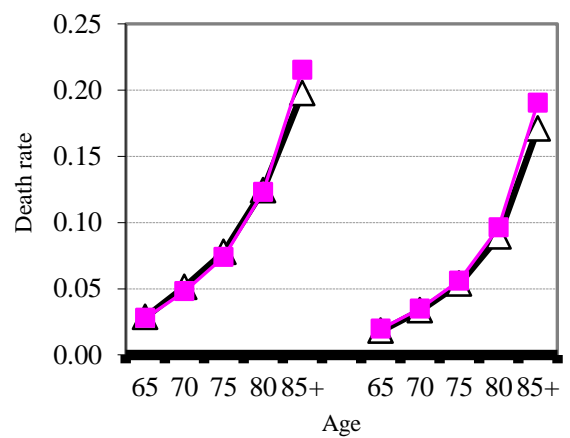

c. Japan

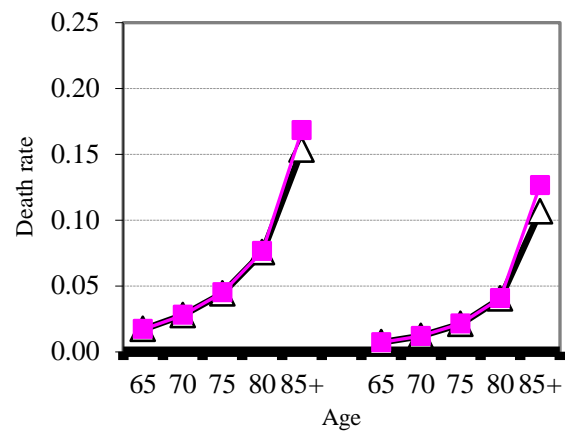

e. Singapore

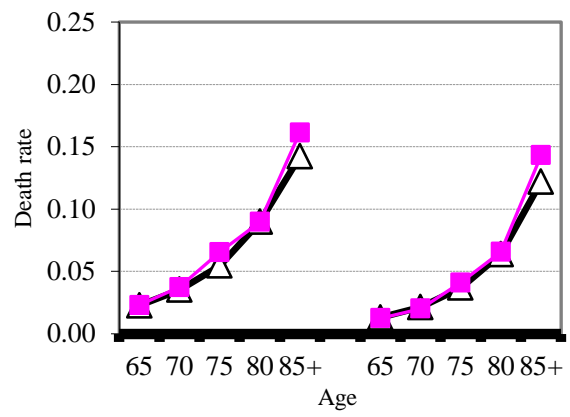

Sources: UNPOP (2013) and WHO (2011). b. Hong Kong

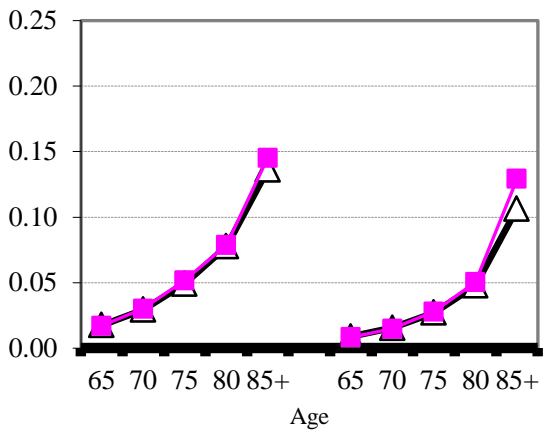

d. Republic of Korea

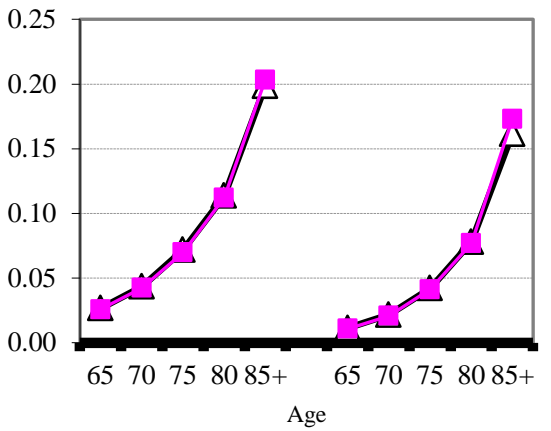

